$N-26$
021634

NASA Technical Memorandum 110310

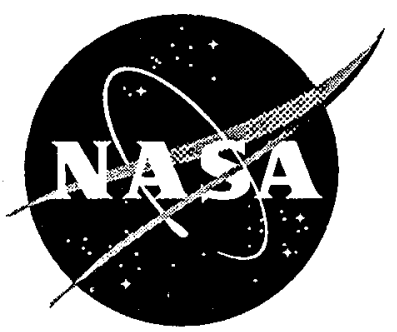

\title{
The Merging of Fatigue and Fracture Mechanics Concepts: A Historical Perspective
}

J. C. Newman, Jr.

Langley Research Center, Hampton, Virginia

January 1997

National Aeronautics and Space Administration Langley Research Center Hampton, Virginia 23681-0001 

J. C. Newman, Jr. ${ }^{1}$

THE MERGING OF FATIGUE AND FRACTURE MECHANICS CONCEPTS: A HISTORICAL PERSPECTIVE *

REFERENCE: Newman, J. C., Jr., "The Merging of Fatigue and Fracture Mechanics Concepts: A Historical Perspective," Fatigue and Fracture Mechanics: 28th Volume, ASTM STP 1321, J. H. Underwood, B. D. MacDonald, and M. R. Mitchell, Eds., American Society for Testing and Materials, Philadelphia, PA, 1997.

\begin{abstract}
The seventh Jerry L. Swedlow Memorial Lecture presents a review of some of the technical developments, that have occurred during the past 40 years, which have led to the merger of fatigue and fracture mechanics concepts. This review is made from the viewpoint of "crack propagation." As methods to observe the "fatigue" process have improved, the formation of fatigue micro-cracks have been observed earlier in life and the measured crack sizes have become smaller. These observations suggest that fatigue damage can now be characterized by "crack size." In parallel, the crack-growth analysis methods, using stress-intensity factors, have also improved. But the effects of material inhomogeneities, crack-fracture mechanisms, and nonlinear behavior must now be included in these analyses. The discovery of crack-closure mechanisms, such as plasticity, roughness, and oxide/corrosion/fretting product debris, and the use of the effective stressintensity factor range, has provided an engineering tool to predict small- and large-crackgrowth rate behavior under service loading conditions. These mechanisms have also provided a rationale for developing new, damage-tolerant materials. This review suggests that small-crack growth behavior should be viewed as typical behavior, whereas largecrack threshold behavior should be viewed as the anomaly. Small-crack theory has unified "fatigue" and "fracture mechanics" concepts; and has bridged the gap between safe-life and durability/damage-tolerance design concepts.
\end{abstract}

KEYWORDS: fatigue, fracture mechanics, microstructure, cracks, surface cracks, stress-intensity factor, J-integral, fatigue crack growth, crack closure, elasticity, plasticity, finite element method, constraint

In 1965, ASTM Committee E24 on Fracture Testing of Metallic Materials was formed to promote the rapid growth of the field of Fracture Mechanics. Committee E09 on Fatigue had already been in existence for nearly two decades. With the recent merger of Committees

\footnotetext{
* Seventh Annual Jerry L. Swedlow Memorial Lecture

${ }^{1}$ Senior Scientist, NASA Langley Research Center, Hampton, Virginia, 23681-0001.
} 
E09 and E24 to form Committee E08 in 1993, it seems appropriate to explore the merging of fatigue and fracture mechanics concepts in a forum that honors and remembers Professor Jerry L. Swedlow, who incidentally completed his Ph.D. Thesis also in 1965 [1].

Since the 1950's, events in the naval, nuclear, and aircraft industries have fostered the development of the field of fracture mechanics. The failure of the Comet transport jet aircraft [2] from fatigue cracks gave rise to treatments of crack propagation using notch-root parameters and the stress-intensity factor concept of Irwin [3] and Paris et al. [4,5]. Crack propagation theories would eventually form the bridge that would link fatigue and fracture mechanics concepts. The notch-root local-stress approach hinged upon the Neuber [6] or Hardrath-Ohman [7] equations which related local plastic stresses and strains to the elastic stress concentration. Later, Hutchinson [8] and Rice [9] noted some similarities between Neuber's elastic-plastic relation for notches and their solutions for elastic-plastic behavior of cracks. Using a notch-root parameter, $\mathrm{K}_{\mathrm{tn}} \mathrm{S}_{\text {net }}$ for a sharp notch or crack, McEvily and Illg $[10]$ correlated fatigue-crack-growth rates in a very similar manner to the current $\Delta \mathrm{K}$-rate concept. Years later, this notch-root parameter was shown to be directly related to the stressintensity factor [5]. But the elegance and simplicity of the stress-intensity factor concept rapidly developed into the durability and damage tolerance concepts currently used today to design fatigue- and fracture-critical components. The next major link between fatigue and fracture mechanics was the discovery of fatigue-crack closure by Elber [11]. The crackclosure concept put crack-propagation theories on a firm foundation and allowed the development of practical life-prediction methods for variable-amplitude and spectrum loading, such as experienced by modern-day commercial aircraft.

In the mid-1970's, Pearson [12] and Kitagawa [13] showed that short cracks (less than about $0.5 \mathrm{~mm}$ in length) grew much faster than long cracks when correlated against the stressintensity factor range. During the next two decades, short- or small-crack research formed the final link between fatigue and fracture mechanics. These studies, conducted by many worldwide organizations [14,15], the AGARD Structures and Materials Panel [16-18], ASTM Committees E9 and E24 [19], NASA and the CAE [20] provided experimental databases and analysis methods to perform fatigue analyses on notch components using "crack propagation" theories. The small-crack theory (treatment of fatigue as the growth of micro-cracks, 1 to 20 $\mu \mathrm{m}$ in length) has been applied to many engineering materials with reasonable success. Although this review will concentrate mainly on a fracture-mechanics viewpoint, the local notch-root stresses and strains from classical fatigue analyses are the driving forces behind the initiation and growth of small cracks at material discontinuities or manufacturing defects. The merging of fatigue and fracture mechanics concepts will provide industries with a unified approach to life prediction. Small-crack theory can now be used to assess the influence of material defects and manufacturing or service-induced damage on fatigue life behavior. This approach will ultimately improve the reliability and economic usefulness of many structures.

The review will begin with some fatigue and fatigue-crack growth observations that have set the stage for the treatment of fatigue from a fracture-mechanics viewpoint. This treatment hinges strongly upon whether fracture-mechanics parameters can be used to model micro- or small-crack growth rate behavior. The development of the stress-intensity factor and some 
nonlinear fracture-mechanics parameters, such as the $\mathrm{J}$ and $\mathrm{T}^{*}$ integrals, and their application to small-crack behavior will be discussed. The application of linear elastic fracture mechanics, i.e. the stress-intensity-factor range, $\Delta \mathrm{K}$, to the "small or short" crack-growth regime has been actively studied and questioned for more than two decades. Various nonlinear crack-tip parameters and crack-closure effects were introduced to help explain the differences between small- and large-crack growth rate behavior. A key element in these nonlinear crack-tip parameters is crack closure. A brief survey of the finite-element and finite-difference analyses that have been conducted to study the fatigue-crack growth and closure processes; and some typical results will be given. A review of some of the more popular yield-zone models, empirical crack-closure models, and the analytical crack-closure (modified Dugdale or stripyield) models will be discussed. The application of some of these models to predict crack growth under aircraft spectrum load histories will be presented. Constraint or threedimensional stress state effects play a strong role in the fatigue initiation and crack-growth process. For example, plasticity-induced crack closure (yielded material at the crack tip and in the wake of the advancing crack) is greatly affected by plane-stress or plane-strain behavior. The most common constraint parameters, and their use in fatigue-crack growth relations, will be discussed. The evolution of some of the proposed fatigue-crack-growth rate relations will then be reviewed. Some observations on the effects of microstructure, environment, and loading on fatigue-crack-growth rate behavior will be discussed. These observations are important in developing the intrinsic crack-growth-rate relations to calculate crack growth under general cyclic loading. The small-crack growth rate data presented by Pearson [12], and enlarged upon by Lankford [2I], will be presented and discussed. An analysis of the Pearson and Lankford small-crack data reveals an important conclusion about the relevance of the large-crack thresholds. The prediction of fatigue life, on the basis of crack propagation from microstructural features, such as inclusions or voids, will be presented for several materials and loading conditions. A design concept using "small-crack theory" will be discussed.

This review is necessarily limited in scope and will not be able to fully cover the vast amount of research that has been conducted over the past 40 years in the fields of fatigue and fracture mechanics. Several excellent books and articles on the "merging of fatigue and fracture mechanics concepts" have helped set the stage for this paper. The book by Fuchs and Stephens [22] presents a brief history on the subject, the book entitled "Fatigue Crack Growth - 30 Years of Progress" edited by Smith [23] gives excellent reviews on a variety of technical subjects, and the paper on "History of Fatigue" by Schütz [24] gives a historical perspective. The author request the readers indulgence and forgiveness if some major events have been omitted unintentionally, or if reference is not made to all of those who have made significant contributions to the subject. As pointed out by Paris in the Third Swedlow Lecture [25], "History has a strong tendency to be one man's personal recollection of important events ...". This review is no different. 


\section{FATIGUE AND FATIGUE CRACK GROWTH OBSERVATIONS}

The fatigue life, as presented by Schijve [26], is divided into several phases: crack nucleation, micro-crack growth, macro-crack growth, and failure, as shown in Fig. 1. Crack nucleation is associated with cyclic slip and is controlled by the local stress and strain concentrations, and notch constraint. Although the slip-band mechanism of crack formation may be necessary in pure metals, the presence of inclusions or voids in engineering metals will greatly affect the crack-nucleation process. Micro-crack growth, a term now referred to as the "small-crack growth" regime, is the growth of cracks from inclusions, voids, or slip bands, in the range of 1 to $10 \mu \mathrm{m}$ in length. Schijve [27] has shown that for polished surfaces of pure metals and for commercial alloys, the formation of a small crack to about $100 \mu \mathrm{m}$ in size can consume 60 to $80 \%$ of the fatigue life. This is the reason that there is so much interest in the growth behavior of small cracks. Macro-crack growth and failure are regions where fracture-mechanics parameters have been successful in correlating and in predicting fatigue-crack growth and fracture. This review will highlight the advances that have been made in the use of the same fracture-mechanics parameters in the treatment of micro- or small-crack growth using continuum-mechanics approaches.

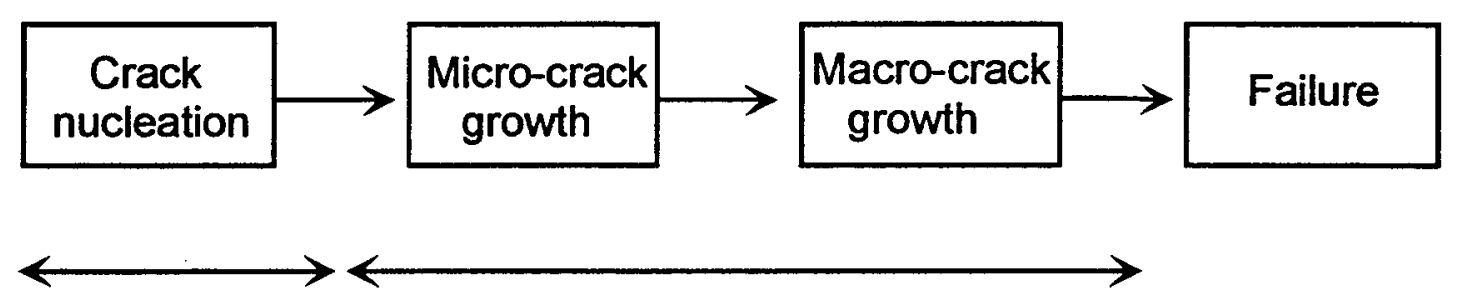

Initiation

$\mathrm{K}_{\mathrm{T}}, \mathrm{K}_{\sigma}, \mathrm{K}_{\varepsilon}$

Stress and strain concentration, notch constraint

\section{Crack growth}

Fracture

$K_{I c}, K_{c}, J_{I c}, C T O D$
Microstructure, geometry, loading, crack-front constraint

FIG. 1--Different phases of fatigue life and relevant factors (modified after Schijve, 1979 [27]).

One of the earliest observations on the mechanism of small-crack growth was made by Forsyth [28]. He showed that the initiation and early growth of small cracks can occur at a single slip system (Stage I crack growth) in a favorably oriented surface grain, as shown in Fig. 2(a). Slip-band cracking is promoted by high stresses and higher alloy purity, such as observed in cladding on aluminum alloys. The transition from Stage I to a crack-growth mechanism involving multiple slip systems at the crack tip (Stage II) can occur at or near the first grain boundary encountered by the crack. As might be expected, grain boundaries can have a significant effect on the growth of small cracks. The grain 
boundaries contribute greatly to the scatter that is observed in small-crack growth rate behavior.

All materials are anisotropic and inhomogeneous when viewed at a sufficiently small scale. For example, engineering metals are composed of an aggregate of small grains. Inhomogeneities, see Fig. 2(b), exist not only due to the grain structure, but also due to the presence of inclusion particles or voids. These inclusion particles are of a different chemical composition than the bulk material, such as silicate or alumina inclusions in steels. Because of the nonuniform microstructure, local stresses may be concentrated at these locations and may cause fatigue cracks to initiate. Crack initiation is primarily a surface phenomenon because: (1) local stresses are usually highest at the surface, (2) an inclusion particle of the same size has a higher stress concentration at the surface than in the interior, (3) the surface is subjected to adverse environmental conditions, and (4) the surfaces are susceptible to inadvertent damage. The growth of "natural" surface initiated cracks in commercial aluminum alloys has been investigated by Bowles and Schijve [29], Morris et al. [30] and Kung and Fine [3I]. In some cases, small cracks initiated at inclusions and the Stage I period of crack growth was eliminated, as shown in Fig. 2(b). This tendency toward inclusion initiation rather than slip-band (Stage I) cracking was found to depend on stress level and inclusion content [31]. Similarly, defects (such as tool marks, scratches and burrs) from manufacturing and service-induced events will also promote initiation and Stage II crack growth, as shown in Fig. 2(c).

In 1956, Hunter and Fricke [32] conducted rotating beam tests on chemicallypolished un-notched specimens made of 6061-T6 aluminum alloy. Testing was interrupted periodically in order to obtain plastic replicas of the specimen surface. These replicas reproduced the surface details and provided direct measurement of cracks. The stress-

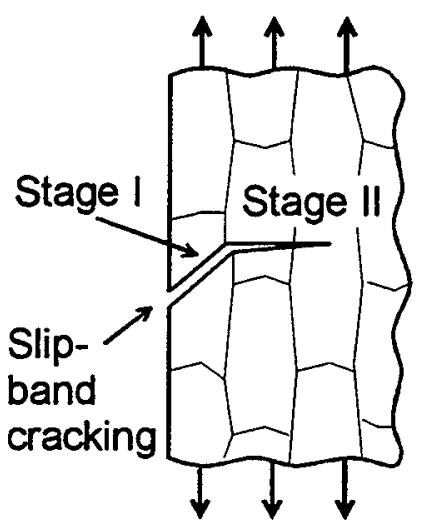

(a)

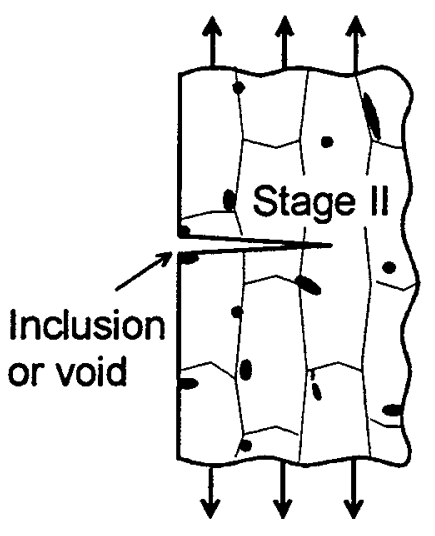

(b)

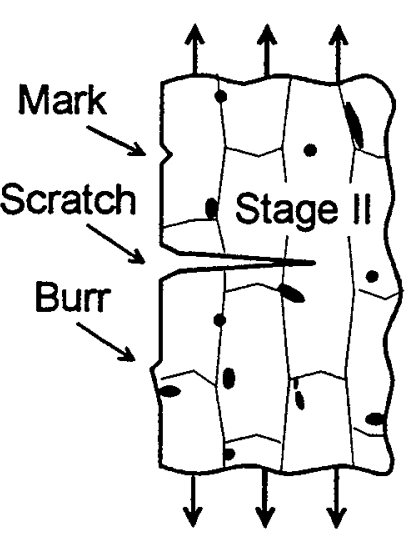

(c)

Stages of fatigue process Influence of inclusions or voids

Influence of service-induced or manufacturing defects

FIG. 2--Stages of the fatigue-crack-growth process (after Forsyth, 1962 [28]; after Morris, Buck and Marcus, 1976 [30]). 
cycles (S-N) relation between the "first" crack observed and failure is shown in Fig. 3. (No crack length was defined for the first crack, but crack length data was presented for lengths greater than about $0.1 \mathrm{~mm}$.) These tests revealed that at high stresses, crack propagation was a dominate part of life, whereas at low stresses, near the endurance limit, crack nucleation was dominant. Their results on crack-length-against-cycles from 0.1 to 1 $\mathrm{mm}$ did not show any abnormal behavior (i.e., rates were a monotonically increasing function of crack length).

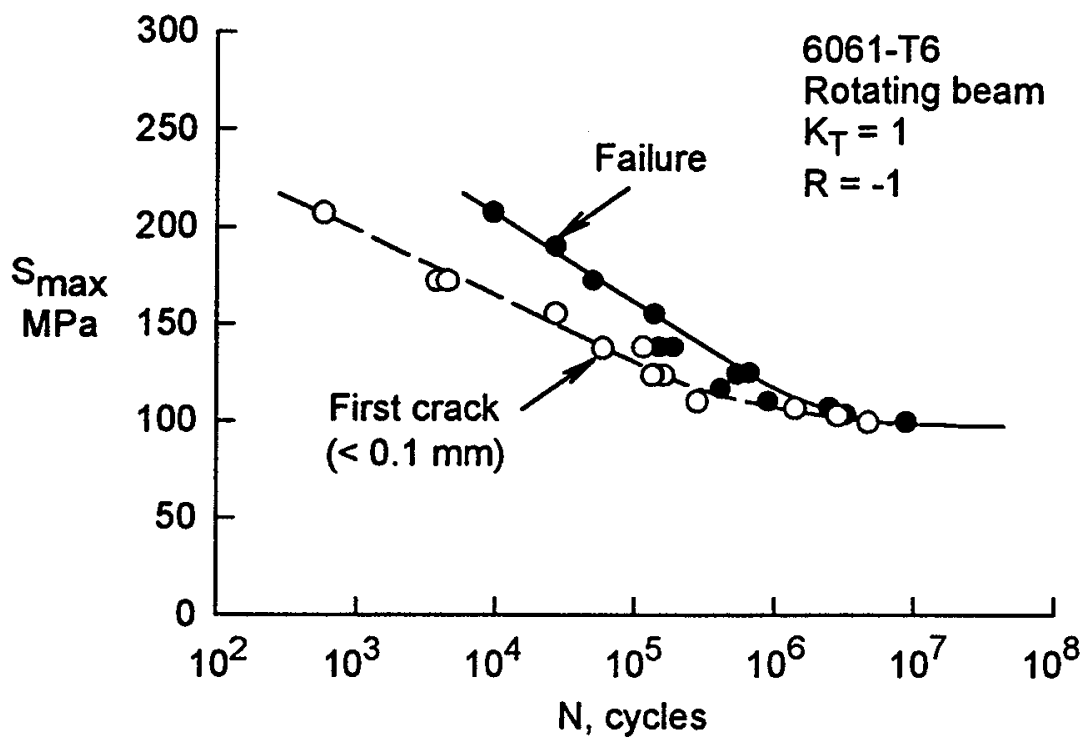

FIG. 3--Stress-life curves for rotating beams under constant-amplitude loading (after Hunter and Fricke, 1956 [32]).

Newman and Edwards [17], in an AGARD cooperative test program involving several laboratories, found similar results under an aircraft load spectrum, FALSTAFF, on chemically-polished notched specimens made of 2024-T3 aluminum alloy. Replicas were also used to monitor crack initiation and crack growth from $10 \mu \mathrm{m}$ to $2.3 \mathrm{~mm}$. The stresslife curves for lives to a given crack length are shown in Fig. 4. These results show that crack growth is the dominant part of life (about $90 \%$ ) for the limited range of stress levels tested. Similar results were also found for the Gaussian load spectrum and various constant-amplitude loading conditions $(R=-2,-1,0$ and 0.5$)$ with stress levels above and near the endurance limit. For all loading conditions, 80 to 90 percent of the fatigue life was spent as crack growth from a crack length of $20 \mu \mathrm{m}$ to failure (inclusion-particle cluster sizes at the initiation sites ranged from 2 to $7 \mu \mathrm{m}$ in length). How much of the fatigue life is consumed by crack growth from a crack of the inclusion-particle size to 20 $\mu \mathrm{m}$ is left to conjecture, but it could easily account for 5 to 10 percent of the total life. 


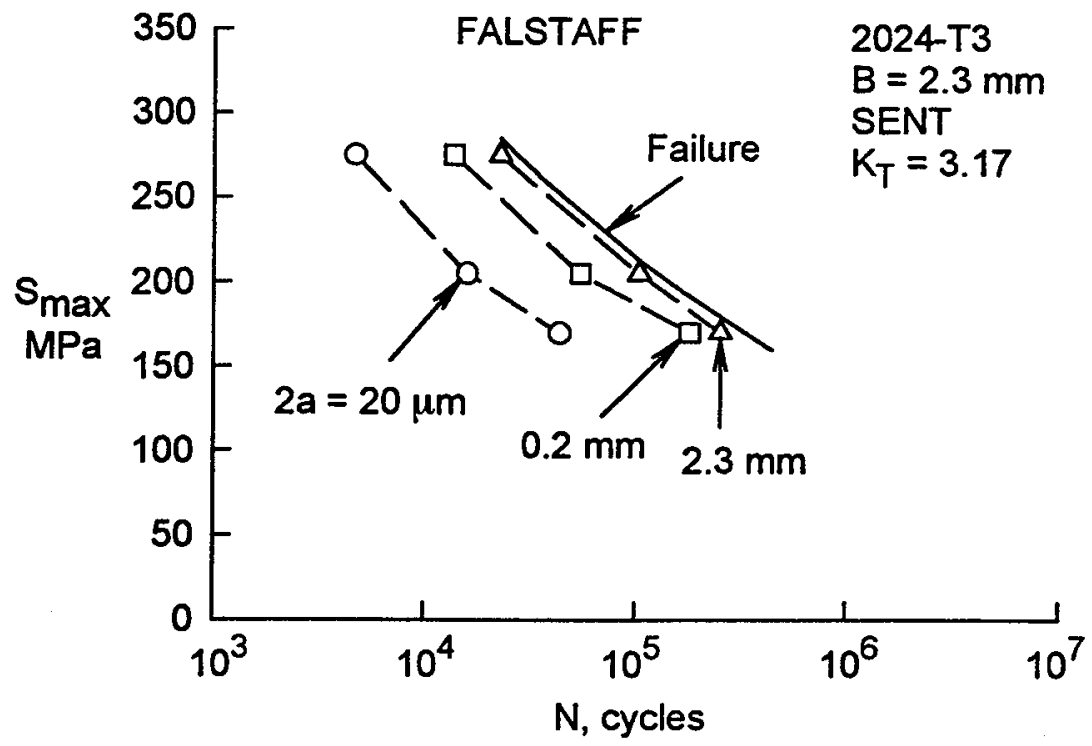

FIG. 4--Stress-life curves for single-edge-notch tensile (SENT) specimens under aircraft spectrum loading (after Newman and Edwards, 1988 [17]).

Elber [33], in 1968, observed that fatigue-crack surfaces contact with each other even during tension-tension cyclic loading. This contact is due to residual plastic deformation that is left in the wake of an advancing crack, as illustrated in Fig. 5(a). This deformed material contacts during unloading. It is surprising that this observation appeared so many years after crack growth was first studied. But this simple observation and the explanation of the crack-closure mechanism (or more properly crack-opening) began to explain many crack-growth characteristics almost immediately. Since the discovery of plasticity-induced closure, several other closure mechanisms, such as roughness- and oxide/corrosion/fretting product-induced closure, have been identified. The roughness mechanism, discovered by Beevers and his coworkers [34, 35], appears to be most prevalent in the near-threshold regime of large-crack growth where the maximum plastic-zone sizes are typically less than the grain size [36]. At these low stress levels, crack extension is primarily along a single slip system resulting in a Stage I-like mechanism and a serrated or zig-zag ( $\pm \theta$ deg.) crack-growth path, as shown in Fig. 5(b). These cracks will have mixed-mode (Mode I and II) crack-surface deformations, which provide the mechanism for contact between the surfaces during cyclic loading. Cracks growing along a non-planar path, such as during overloads in aluminum alloys, will develop surface contact and create debris due to fretting and the growth of oxides from the newly created crack surfaces, see Fig. 5(c). This debris will cause premature contact, as discussed by Paris et al. [37] and Suresh et al. [38]. These new closure mechanisms, and the influence of the plastic wake on local crack-tip strain field, have greatly advanced the understanding of the fatigue-crack growth process. A brief review of some of the numerical analyses and models of the crack-closure phenomenon will be presented later. 


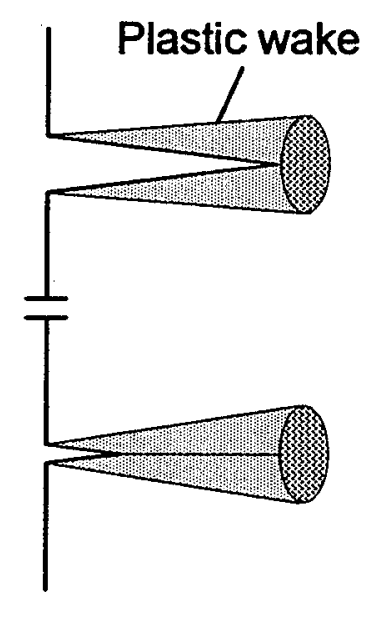

(a) Plasticity-induced
closure

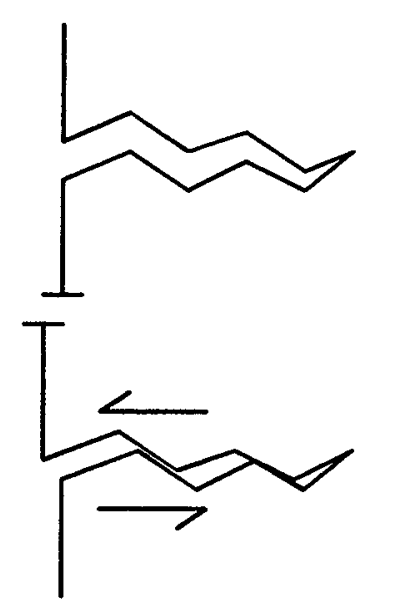

(b) Roughness-induced closure

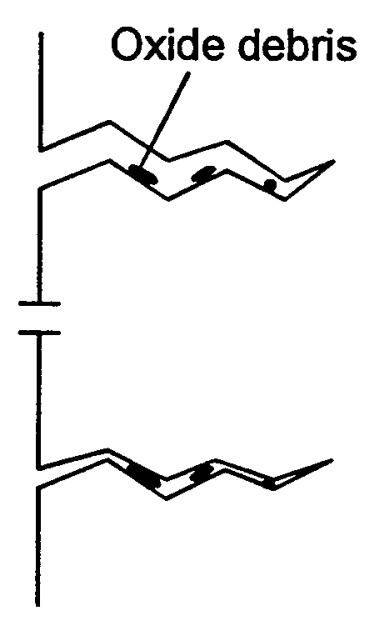

(c) Oxide/corrosion productinduced closure

FIG. 5--Dominant fatigue-crack-closure mechanisms (after Suresh and Ritchie, 1982 [36]).

\section{STRESS-INTENSITY FACTORS}

The essential feature of fracture mechanics is to characterize the local stress and deformation fields in the vicinity of a crack tip. In 1957, Irwin [3, 39] and Williams [40] recognized the general applicability of the field equations for cracks in isotropic elastic bodies. Under linear elastic conditions, the crack-tip stresses have the form:

$$
\sigma_{i j}=K(2 \pi r)^{-1 / 2} f_{i j}(\theta)+A_{2} g_{i j}(\theta)+A_{3} h_{i j}(\theta) r^{1 / 2}+\ldots
$$

where $\mathrm{K}$ is the Mode $\mathrm{I}$ stress-intensity factor; $\mathrm{r}$ and $\theta$ are the radius and polar angle measured from the crack tip and crack plane, respectively; $A_{i}$ are constants; $f_{i j}(\theta), g_{i j}(\theta)$ and $h_{i j}(\theta)$ are dimensionless functions of $\theta$. The stress fields for both two- and three-dimensional cracked bodies are given by equation (1). After some 30 years, the stress-intensity factors for a large number of crack configurations have been generated; and these have been collated into several handbooks (see for example Refs. 41 and 42). The use of $\mathrm{K}$ is meaningful only when smallscale yielding conditions exist. Plasticity and nonlinear effects will be covered in the next section.

Because fatigue-crack initiation is, in general, a surface phenomenon, the stress-intensity factors for a surface- or corner-crack in a plate or at a hole, such as those developed by Raju and Newman $[43,44]$, are solutions that are needed to analyze small-crack growth. Some of these solutions are used later to predict fatigue-crack growth and fatigue lives for notched specimens made of a variety of materials. 


\section{ELASTIC-PLASTIC OR NONLINEAR CRACK-TIP PARAMETERS}

Analogous to the stress field for a crack in an elastic body, Hutchinson, Rice and Rosengren (HRR) $[8,45]$ derived the asymptotic stress and strain field for a stationary crack in a nonlinear elastic body. The first term for a power-hardening solid was given by:

$$
\begin{aligned}
& \sigma_{i j}=\left[E^{\prime} J /\left(\sigma_{o}{ }^{2} r\right)\right]^{n /(n+1)} \sigma_{o} f_{i j}(\theta, n) \\
& \varepsilon_{i j}=\left[E^{\prime} J /\left(\sigma_{o}{ }^{2} r\right)\right]^{1 /(n+1)} g_{i j}(\theta, n)
\end{aligned}
$$

where $J$ is the path-independent integral of Rice [9], $E^{\prime}$ is the elastic modulus $\left(E^{\prime}=E\right.$ for plane stress or $E^{\prime}=E /\left(1-v^{2}\right)$ for plane strain), $\sigma_{o}$ is the flow stress, $n$ is the strain-hardening coefficient ( $n=0$ is perfectly plastic and $n=1$ is linear elastic), $r$ and $\theta$ are the radius and polar angle measured from the crack tip and crack plane, respectively, and $\mathrm{f}_{\mathrm{jj}}(\theta, n)$ and $\mathrm{g}_{\mathrm{jj}}(\theta, \mathrm{n})$ are dimensionless functions depending upon whether plane-stress or plane-strain conditions are assumed.

\section{$\underline{\mathrm{J} \text { and }} \mathrm{T}^{*}$ Path Integrals}

The J-integral appeared in the works of Eshelby [46], Sanders [47], and Cherepanov [48], but Rice [9] provided the primary contribution toward the application of the pathindependent integrals to stationary crack problems in nonlinear elastic solids. The Jintegral, defined in Fig. 6, has come to receive widespread acceptance as an elastic-plastic fracture parameter. Landes and Begley [49] and others have used the J-integral as a nonlinear crack-tip parameter to develop crack initiation $\mathrm{J}_{\mathrm{Ic}}$ values and $\mathrm{J}-\mathrm{R}$ curves for a variety of materials. However, because deformation theory of plasticity, instead of incremental theory, was used in its derivation, the J-integral is restricted to limited amounts of crack extension in metals.

In 1967, Cherepanov [48,50] derived an invariant integral (denoted $\Gamma$ ) that is valid for the case of a moving crack with arbitrary inelastic properties, such as an elastic-plastic material. (Both Rice and Atluri have used the symbol $\Gamma$ to denote a contour around the crack tip. This should not be confused with Cherepanov's definition of his $\Gamma$-integral.) Atluri and his coworkers [51,52] overcame experimental and numerical difficulties in evaluating the $\Gamma$ parameter (denoted as $T^{*}$, see Fig. 6) for a moving crack. The $T^{*}$-integral is beginning to receive more attention in the literature.

\section{Cyclic Crack-Tip Parameters}

Both the J-and $\mathrm{T}^{*}$-integrals have been extended to apply to applications involving cyclic loading. Dowling and Begley [53] developed an experimental method to measure the cyclic $\mathbf{J}$ values from the area under the load-against-deflection hysteresis loop that accounted for the effects of crack closure. The $\Delta \mathrm{J}_{\mathrm{eff}}$ parameter has been successfully used to correlate fatigue- 
crack-growth rate data from small- to large-scale yielding conditions for tension and bending loads [54]. Similarly, Atluri et al. [52] have derived the $\Delta T^{*}$ integral (see Fig. 6) for cyclic loading and others [55] are beginning to evaluate the parameter under cyclic loading.
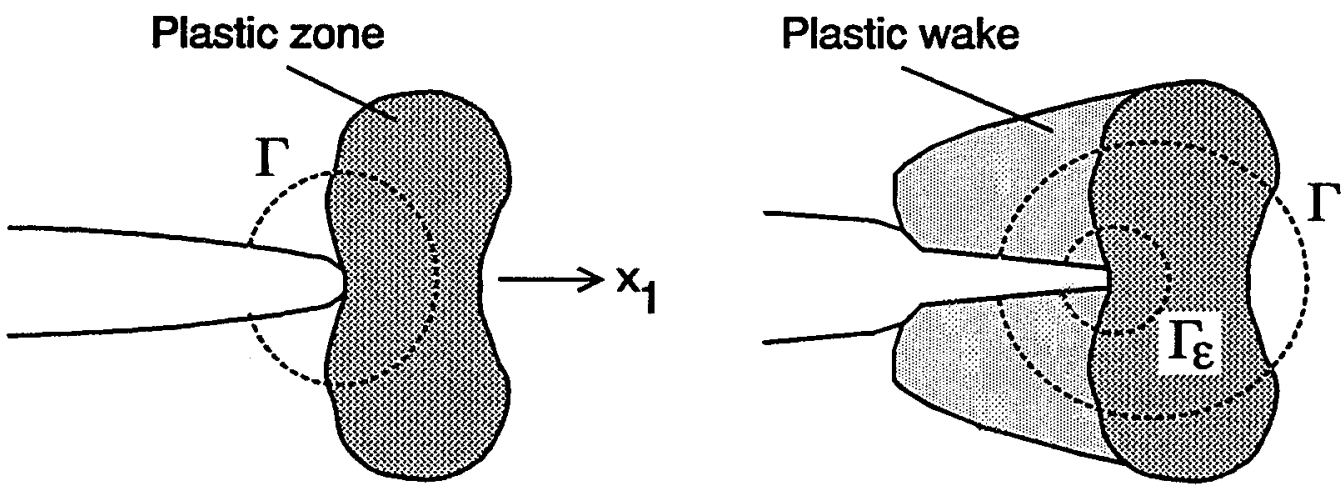

Rice (1968):

Atluri (1982):

$$
J=\int_{\Gamma}\left(W n_{1}-t_{i} u_{i, 1}\right) d \Gamma
$$$$
T^{*}=J-\int_{V-V_{\varepsilon}}\left[W, 1-\left(\sigma_{i j} \varepsilon_{i j, 1}\right)\right] d V
$$

Dowling and Begley (1976):

Atluri, Nishioka and Nakagaki (1984):

$$
\Delta J_{\text {eff }}=2 A_{c} / B b \quad \Delta T^{*}=\int_{\Gamma_{\varepsilon}}\left(\Delta W n_{1}-\left(t_{i}+\Delta t_{i}\right) \Delta u_{i, 1}-\Delta t_{i} u_{i, 1}\right) d \Gamma
$$

FIG. 6--Elastic-plastic crack-tip parameters.

Plastic Stress-Intensity Factors and the Dugdale Model

In 1960, Irwin [56] developed a simple approach to modify the elastic stressintensity factor to "correct" for plastic yielding at the crack tip. The approach was to add the plastic-zone radius to the crack length and, thus, calculated a "plastic" stress-intensity factor at the "effective" crack length $\left(c+r_{y}\right)$. The size of the plastic zone was estimated from equation (1) as

$$
r_{y}=\alpha_{i}\left(K / \sigma_{y s}\right)^{2}
$$

where $\alpha_{i}=1 /(2 \pi)$ for plane stress and $\alpha_{i}=1 /(6 \pi)$ for plane strain. The term $\alpha_{i}$ is Irwin's constraint parameter that accounts for three-dimensional stress state effects on yielding. Note that equation (4) gives approximately the "radius" of the plastic zone because of a redistribution of local crack-tip stresses due to yielding, which is not accounted for in the 
elastic analysis. The actual plastic-zone size is roughly $2 r_{y}$. Based on test experience, the fracture toughness, $\mathrm{K}_{\mathfrak{c}}$, calculated at the effective crack length remained nearly constant as a function of crack length and specimen width for several materials until the net-section stress exceeded 0.8 times the yield stress ( $\sigma_{\mathrm{ys}}$ ) of the material [57].

Many researchers have used the Dugdale-Barenblatt (DB) model [58,59] to develop some nonlinear crack-tip parameters (see Refs. 60 and 61 ). Drucker and Rice [62] presented some very interesting observations about the model. In a detailed study of the stress field in the elastic region of the model under small-scale yielding conditions, they reported that the model violates neither the Tresca nor von Mises yield criteria. They also found that for two-dimensional, plane-stress, perfect-plasticity theory, the DB model satisfies the plastic flow rules for a Tresca material. Thus, the model represents an exact two-dimensional plane-stress solution for a Tresca material even up to the plastic-collapse load. Therefore, the J-integral calculations from Rice [9] and $\Delta \mathrm{J}$ estimates may be reasonable and accurate under certain conditions. Of course, the application of the DB model to strain-hardening materials and to plane-strain conditions may raise serious questions because plane-strain yielding behavior is vastly different than that depicted by the model.

Rice [9] evaluated the J integral from the DB model for a crack in an infinite body and found that

$$
\mathrm{J}=\sigma_{\mathrm{o}} \delta=8 \sigma_{\mathrm{o}}{ }^{2} \mathrm{c} /(\pi \mathrm{E}) \ln \left[\sec \left(\pi \mathrm{S} / 2 \sigma_{\mathrm{o}}\right)\right]
$$

where $\sigma_{\mathrm{o}}$ is the flow stress, $\delta$ is the crack-tip-opening displacement, $\mathrm{c}$ is the crack length, $\mathrm{E}$ is the elastic modulus, and $\mathrm{S}$ is the applied stress. An equivalent plastic stress-intensity factor $\mathrm{K}_{\mathrm{J}}$ is given as

$$
\mathrm{KJ}_{\mathrm{J}}^{2}=\mathrm{JE} /\left(1-\eta^{2}\right)
$$

where $\eta=0$ for plane stress, and $\eta=v$ (Poisson's ratio) for plane strain. DB model solutions for plastic-zone size, $\rho$, and crack-tip opening displacement, $\delta$, are available for a large number of crack configurations (see Ref. 4l). Thus, $\mathrm{J}$ and $\mathrm{K}_{\mathrm{J}}$ can be calculated for many crack configurations. However, for complex crack configurations, such as a through crack or surface crack at a hole, closed-form solutions are more difficult to obtain. A simple method was needed to estimate $J$ for complex crack configurations. A common practice in elastic-plastic fracture mechanics has been to add a portion of the plastic zone $\rho$ to the crack length, like Irwin's plastic-zone correction [56], to approximate the influence of crack-tip yielding on the crack-driving parameter.

Newman [63] defined a plastic-zone corrected stress-intensity factor as

$$
K_{p}=S(\pi d)^{1 / 2} F(d / w, d / r, \ldots)
$$

where $\mathrm{d}=\mathrm{c}+\gamma \rho$ and $\mathrm{F}$ is the boundary-correction factor evaluated at the effective crack 
length. The term $\gamma$ was assumed to be constant and was evaluated for several two- and three-dimensional crack configurations by equating $\mathrm{K}_{\mathrm{p}}$ to $\mathrm{K}_{\mathrm{J}}$. From these evaluations, a value of $1 / 4$ was found to give good agreement up to large values of applied stress to flow stress ratios. To put the value of one-quarter in perspective, Irwin's plastic-zone corrected stress-intensity factor [56] is given by $\gamma$ equal to about 0.4 and Barenblatt's cohesive modulus [59] is given by $\gamma=1$. A comparison of $\mathrm{K}_{e}$ (elastic stress-intensity factor) and $\mathrm{K}_{\mathrm{p}}$, normalized by $\mathrm{K}_{\mathrm{J}}$ and plotted against $\mathrm{S} / \sigma_{\mathrm{o}}$ (applied stress to flow stress) for two symmetrical through cracks emanating from a circular hole is shown in Fig. 7. The dashed curves show $\mathrm{K}_{e}$ and the solid curves show $\mathrm{K}_{\mathrm{p}}$ for various crack-length-to-hole-radii (c/r). The elastic curves show significant deviations while the results from the $\mathrm{K}_{\mathrm{p}}$ equation (eqn. 7) are within about $5 \%$ of $\mathrm{K}_{\mathrm{J}}$ up to an applied stress level of about $80 \%$ of the flow stress.

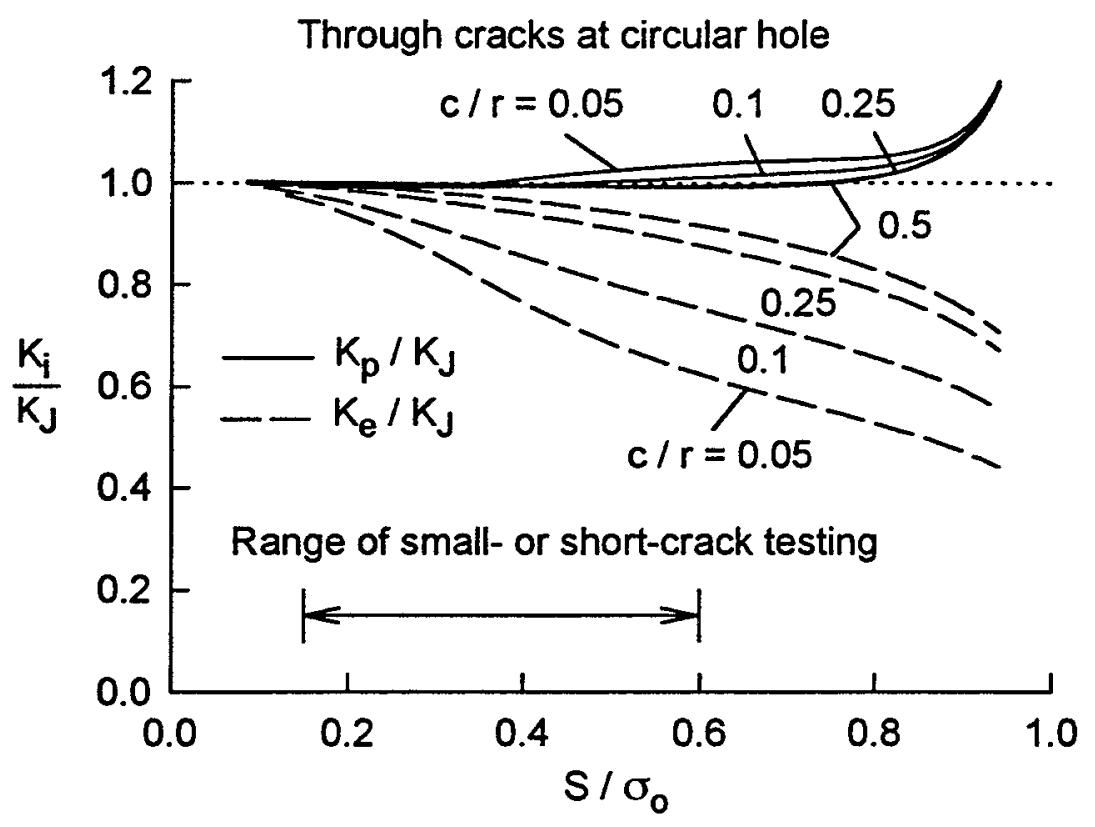

FIG. 7-Ratio of elastic $\mathrm{K}_{\mathrm{e}}$ and plastic $\mathrm{K}_{\mathrm{p}}$ values to equivalent $\mathrm{K}_{\mathrm{J}}$ values (after Newman, 1992 [63]).

This matches well with the 80\%-limit established for Irwin's plastic-zone corrected stressintensity factor, as discussed by McClintock and Irwin [57]. To convert $\mathrm{K}_{\mathrm{p}}$ to $\Delta \mathrm{K}_{\mathrm{p}}$ in equation 7 , the applied stress and flow stress are replaced by $\Delta S$ and $2 \sigma_{0}$, respectively, and $\rho$ is replaced by the cyclic plastic zone $\omega$ (see Ref. 64). Thus, Fig. 7 would be identical for cyclic behavior if $\mathrm{K}_{\mathrm{p}} / \mathrm{K}_{\mathrm{J}}$, is replaced by $\Delta \mathrm{K}_{\mathrm{p}} / \Delta \mathrm{K}_{\mathrm{J}}$ and $S / \sigma_{\mathrm{o}}$ is replaced by $\Delta S /\left(2 \sigma_{0}\right)$, again, with $\gamma=0.25$. Thus, $\Delta \mathrm{K}_{\mathrm{p}}$ is evaluated at a crack length plus one-quarter of the cyclic plastic zone. An application using this parameter to predict the fatigue life under high stresses will be presented later. 


\section{NUMERICAL ANALYSES AND MODELS OF CRACK GROWTH AND CLOSURE}

Since the early 1970 's, numerous finite-element and finite-difference analyses have been conducted to simulate fatigue-crack growth and closure. These analyses were conducted to obtain a basic understanding of the crack-growth and closure processes. Parallel to these numerical analyses, simple and more complex models of the fatigue-crack growth process were developed. Although the vast majority of these analyses and models were based on plasticityinduced crack-closure phenomenon, a few attempts have been made to model the roughnessand oxide-induced crack-closure behavior (see for example Refs. 36 and 65). This section will briefly review: (1) finite-element and finite-difference analyses, (2) yield-zone and empirical crack-closure models, and (3) the modified Dugdale or strip-yield models. In each category, an example of the results will be given.

\section{Finite-Element and Finite-Difference Analyses}

A chronological list of the finite-element and finite-difference analyses [66-88] is given in Table 1. The vast majority of these analyses were conducted using two-dimensional analyses under either plane-stress or plane-strain conditions. Since the mid-1980's, only a few threedimensional finite-element analyses have been conducted. Newman and Armen [66-68] and Ohji et al. [69] were the first to conduct two-dimensional finite-element analyses of the crackclosure process. Their results under plane-stress conditions were in quantitative agreement with the experimental results of Elber $[11]$ and showed that crack-opening stresses were a function of $R$ ratio $\left(\mathrm{S}_{\min } / \mathrm{S}_{\max }\right)$ and stress level $\left(\mathrm{S}_{\max } / \sigma_{\mathrm{o}}\right)$. Nakagaki and Atluri [70] conducted crack-growth analyses under mixed-mode loading and found that cracks did not close under pure Mode II loading. In the mid-1980's, there was a widespread discussion on whether fatigue cracks would close under plane-strain conditions, i.e. where did the extra material to cause closure come from in the crack-tip region, since the material could not deform in the thickness direction, like that under plane-stress conditions. Blom and Holm [72] and Fleck and Newman [76, 79] studied crack-growth and closure under plane-strain conditions and found that cracks did close but the crack-opening levels were much lower than those under plane-stress conditions. Sehitoglu and his coworkers $[74,85]$ found later that the residual plastic deformations that cause closure came from the flanks of the crack (i.e., the material was plastically stretched in the direction parallel to the crack surfaces). Nicholas et al. [77] studied the closure behavior of short cracks and found that at negative $R$ ratios the crackopening levels were negative, i.e. the short cracks were open at a negative load.

In 1992, Llorca [84] was the first to analyze the roughness-induced closure mechanism using the finite-difference method. He found that the key controlling factor in roughnessinduced closure was the tilt angle $(\theta)$ between the crack branches (as the crack zig-zags $\pm \theta$ degrees). Crack-opening loads as high as $70 \%$ of the maximum load were calculated and these results agree with the very high opening loads measured on the 2124-T351 aluminum alloy. 
TABLE 1-- Finite-element analyses of fatigue crack growth and closure.

- Two-Dimensional Cracks

Newman 1974-76

Newman and Armen 1975

Ohji, Ogura and Ohkubo 1975-77

Nakagaki and Atluri 1980

Anquez 1983

Blom and Holm 1985

Kobayashi and Nakamura 1985

Lalor, Sehitoglu and McClung 1986-87

Fleck 1986

Bednarz 1986

Nicholas et al. 1988

Fleck and Newman 1988

Llorca and Galvez (a) 1989

Anquez and Baudin 1988

McClung et al. 1989-94

Llorca (a) 1992

Sehitoglu et al. 1993-96
- Three-Dimensional Cracks

Chermahini 1986

Chermahini et al. 1988-93

Dawicke et al. 1992

Newman 1993

(a) Finite-difference method of analysis.

McClung [80-82] performed extensive finite-element crack-closure calculations on small cracks, crack at holes, and various fatigue-crack growth specimens. Whereas Newman [68] found that $S_{\max } / \sigma_{0}$ could correlate the crack-opening stresses for different flow stresses $\left(\sigma_{0}\right)$ for the middle-crack tension specimen, McClung found that $\mathrm{K}$-analogy, using $\mathrm{K}_{\max } / \mathrm{K}_{\mathrm{o}}$ could correlate the crack-opening stresses for different crack configurations for small-scale yielding conditions. The term $K_{0}=\sigma_{0} \sqrt{ }(\pi a)$ where $\sigma_{0}$ is the flow stress. (K-analogy assumes that the stress-intensity factor controls the development of closure and crack-opening stresses, and that by matching the $\mathrm{K}$ solution among different cracked specimens, an estimate can be made for the crack-opening stresses.) Some typical results are shown in Fig. 8. The calculated crackopening stress, $\mathrm{S}_{\mathrm{op}} / \mathrm{S}_{\max }$ is plotted against $\mathrm{K}_{\max } / \mathrm{K}_{\mathrm{o}}$ for three crack configurations: middlecrack tension $M(T)$, single-edge-crack tension $S E(T)$ and bend $S E(B)$. The symbols show the finite-element calculations for three crack-length-to-width ratios $(\mathrm{c} / \mathrm{w})$. At high values of $\mathrm{K}_{\max } / \mathrm{K}_{\mathrm{o}}$, the crack-opening values became a function of crack configuration. A similar approach using "plastic-zone analogy" may be able to correlate the crack-opening stresses under large-scale yielding. The dashed curve shows the crack-opening stress equation, from the strip-yield model, developed by Newman [89] and recast in term of K-analogy. The 
dashed curve gives a lower bound to the finite-element results. The reason for the differences between the finite-element and strip-yield model results must await further study.

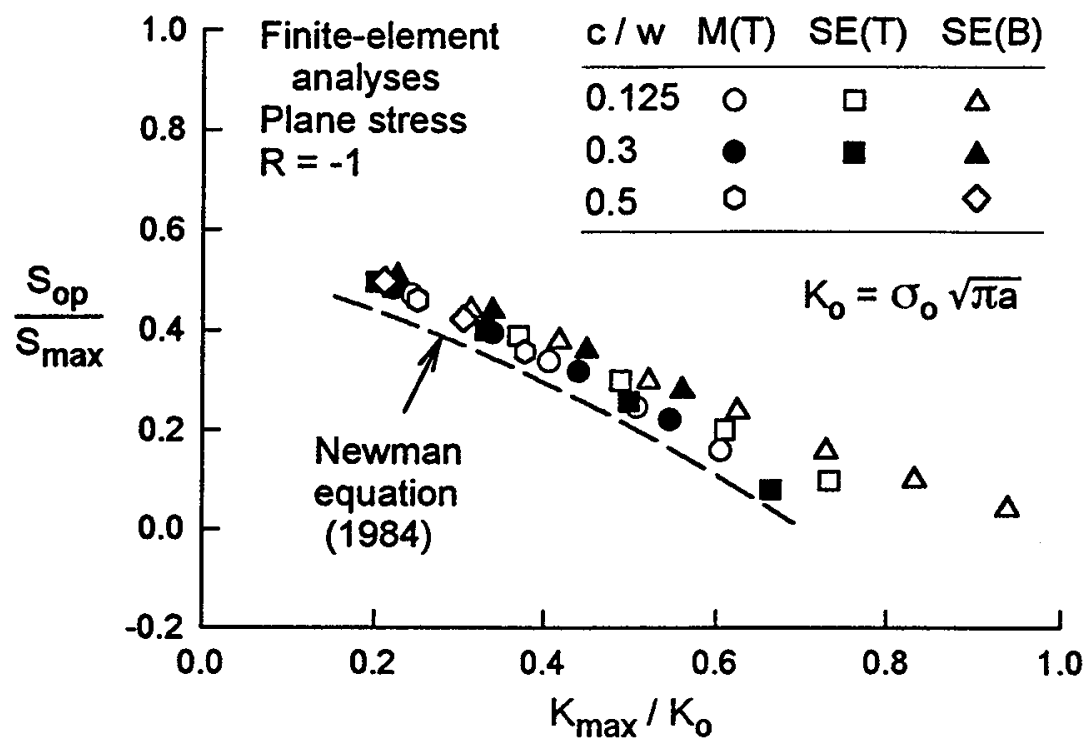

FIG. 8--Configuration effects on crack-opening stresses (after McClung, 1994 [82]).

Very little research on three-dimensional finite-element analyses of crack closure has been conducted. In 1986, Chermahini et al. [86-88] was the first to investigate the threedimensional nature of crack growth and closure. He found that the crack-opening stresses were higher near the free surface (plane stress) region than in the interior, as expected. Later, Dawicke et al. [90] obtained experimental crack-opening stresses, similar to Chermahini's calculations, along the crack front using Sunder's striation method [91], backface-strain gages, and finite-element calculations.

In reviewing the many papers on finite-element analyses, a few analysts were extending the crack at "minimum" load, instead of at maximum load for various reasons. Real cracks do not extend at minimum load and crack-closure and crack-opening behavior calculated from these analyses should be viewed with caution. As is obvious from Table 1, further study is needed in the area of three-dimensional finite-element analyses of crack growth and closure to rationalize the three-dimensional nature of closure with respect to experimental measurements that are being made using crack-mouth and backface-strain gages. Because the measurements give a single value of crack-opening load, what is the relation between this measurement and the opening behavior along the crack front? Is the measurement giving the free surface value, i.e. the last region to open? The crack-opening value in the interior is probably the controlling value because it is dominant over a large region of the crack front $[87,90]$. Also, more analyses are needed on the other forms of closure, such as roughness-induced closure. From the author's point of view, plasticity- and roughness-induced closure work together to close 
the crack and the phenomena are difficult to separate. In Llorca's analyses [84] in the nearthreshold regime, the plastic-zone size was smaller than the mesh points in the finite-difference method. Is the method able to accurately account for the mixed-mode deformation under these conditions? Residual plastic deformations in the normal and shear directions are what causes the crack surfaces to prematurely contact during cyclic loading.

\section{Yield-Zone and Empirical Crack-Closure Models}

A list of some of the more popular yield-zone models [92-97] and empirical crackclosure models [98-102] is given in Table 2. The Wheeler [92] and Willenborg et al. [93] models were the first models proposed to explain crack-growth retardation after overloads. These models assume that retardation exists as long as the current crack-tip plastic zone is enclosed within the overload plastic zone. The physical basis for these models, however, is weak because they do not account for crack-growth acceleration due to underloads or immediately following an overload. Chang and Hudson [103] clearly demonstrated that retardation and acceleration are both necessary to have a reliable model. Later models by Gallagher [94], Chang [95] and Johnson [96] included functions to account for both retardation and acceleration. A new generation of models was introduced by Bell and Wolfman [98], Schijve [99], de Koning [100], Baudin et al. [101] and Aliaga et al. [102] that were based on the crack-closure concept. The simplest model is the one proposed by Schijve, who assumed that the crack-opening stress remains constant during each flight in a flight-byflight sequence. The other models developed empirical equations to account for retardation and acceleration, similar to the yield-zone models.

TABLE 2-- Empirical yield-zone or crack-closure models.

- Yield-Zone Models

Willenborg et al. 1971

Wheeler 1972

Gallagher (GWM) 1974

Chang (EFFGRO) 1981

Johnson (MPYZ) 1981

Harter (MODGRO) 1988
- Crack-Closure Models

Bell and Wolfman 1976

Schijve 1980

de Koning (CORPUS) 1981

Baudin et al. (ONERA) 1981

Aliaga et al. (PREFAS) 1985

Lazzeri et al. [104] conducted fatigue-crack growth tests on a middle-crack tension specimen under a flight-by-flight load history (ATR-spectrum) at a mean flight stress level $\left(\mathrm{S}_{\mathrm{lg}}\right)$ of $75 \mathrm{MPa}$. Tests results are shown in Fig. 9. These results show an initial high rate of growth followed by a slowing down of crack growth from 7 to $10 \mathrm{~mm}$ and then a steady rise in the overall growth rates until failure. This behavior is what Wanhill [105] calls "transient crack 
growth" under spectrum loading. Lazzeri et al. then made comparisons of the predicted crack length against flights from four of the empirical models (CORPUS, PREFAS, ONERA, and MODGRO, see Table 2) and one strip-yield model (FASTRAN-II, to be discussed later). The predicted results are shown with symbols in Fig. 9. The MODGRO model was very conservative, while the other three empirical models gave essentially the same results but under predicted the flights to failure. The FASTRAN-II model predicted failure at about $15 \%$ shorter than the test results, but this model came closer to modeling the "transient crack growth" behavior, as discussed by Wanhill. This behavior has been traced to the "constraintloss" regime in thin-sheet materials by Newman [106].

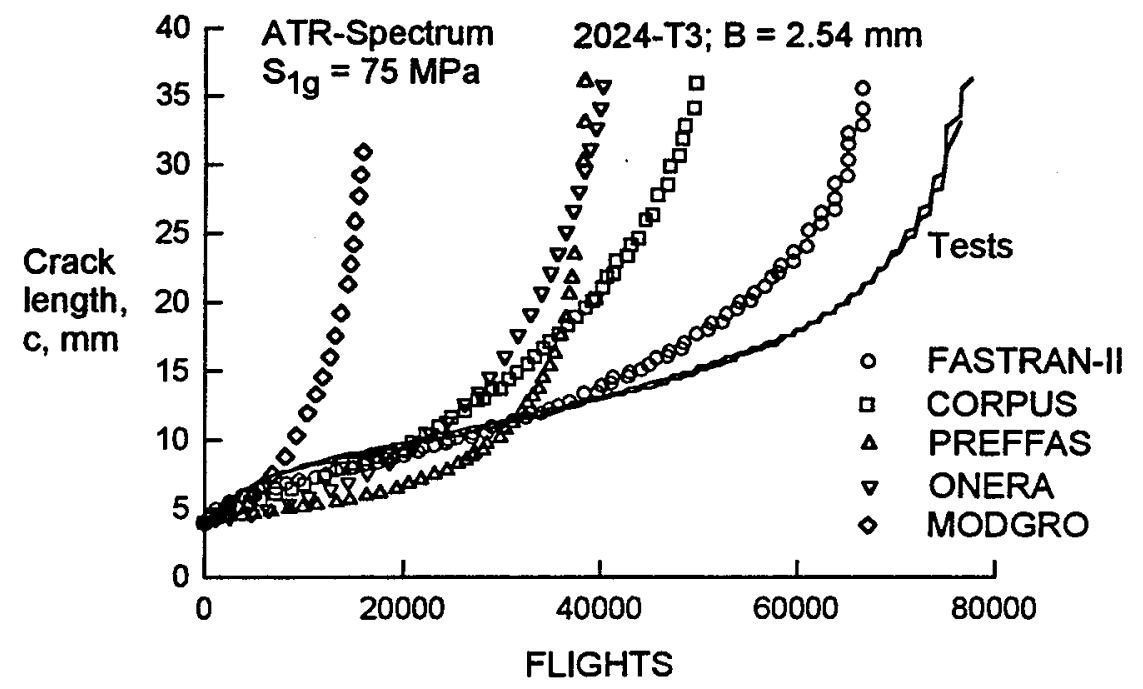

FIG. 9--Comparison of predictions from various models on aircraft spectrum (after Lazzeri et al., 1995 [104]).

\section{Modified Dugdale or Strip-Yield Models}

A chronological list of the modified Dugdale or strip-yield models [107-125] is given in Table 3. Shortly after Elber [33] discovered crack closure, the research community began to develop analytical or numerical models to simulate fatigue-crack growth and closure. These models were designed to calculate the growth and closure behavior instead of assuming such behavior as in the empirical models. Seeger [107] and Newman [66] were the first to develop two types of models. Seeger modified the Dugdale model and Newman developed a ligament or strip-yield model. Later, a large group of similar models were also developed using the Dugdale model framework. Budiansky and Hutchinson [109] studied closure using an analytical model, while Dill and Saff [108], Fuhring and Seeger [111], and Newman [112] modified the Dugdale model. Some models used the analytical functions to model the plastic zone, while others divided the plastic zone into a number of elements. The model by Wang and 
Blom [118] is a modification of Newman's model [112] but their model was the first to include weight-functions to analyze other crack configurations. All of the other models in Table 3 are quite similar to those previously described. The models by Nakai et al. [113], Tanaka [116] and Sehitoglu et al. [85] began to address the effects of microstructure and crack-surface roughness on crack-closure behavior.

TABLE 3--Modified Dugdale or strip-yield crack-closure models.

\begin{tabular}{ll}
\hline Seeger 1973 & Tanaka 1985 \\
Newman 1974 & Ibrahim 1986 \\
Dill and Saff 1976 & Wang and Blom 1987, 1991 \\
Budiansky and Hutchinson 1978 & Chen and Nisitani 1988 \\
Hardrath et al. 1978 & de Koning and Liefting 1988 \\
Fuhring and Seeger 1979 & Keyvanfar and Nelson 1988 \\
Newman 1981, 1990 & Nakamura and Kobayashi 1988 \\
Nakai et al. 1983 & Daniewicz 1991 \\
Sehitoglu 1985 & ten Hoeve and de Koning 1995 \\
Keyvanfar 1985 & Sehitoglu et al. 1996 \\
\hline
\end{tabular}

A typical modified Dugdale model is shown in Fig. 10. This model [110,112] uses bar elements to model the plastic zone and the residual plastic deformations left as the crack grows. Three-dimensional constraint is accounted for by using the constraint factor, $\alpha$. For planestress conditions, $\alpha$ is equal to unity and for plane-strain conditions, $\alpha$ is equal to 3 . The constraint factor has been used to correlate constant-amplitude fatigue crack growth rate data, as will be discussed later.

\section{CONSTRAINT EFFECTS ON CRACK-GROWTH BEHAVIOR}

The importance of constraint effects in the failure analysis of cracked bodies has long been recognized by many investigators. Strain gradients that develop around a crack front cause the deformation in the local region to be constrained by the surrounding material. This constraint produces multiaxial stress states that influence fatigue-crack growth and fracture. The level of constraint depends upon the crack configuration and crack location relative to external boundaries, the material thickness, the type and magnitude of applied loading, and the material stress-strain properties. In the last few years, a concerted effort (see Refs. 126-128) has been undertaken to quantify the influence of constraint on fatigue-crack growth and fracture. To evaluate various constraint parameters, two- and three-dimensional stress analyses have been used to determine stress and deformation states for cracked bodies. The constraint parameters that are currently under investigation are (1) Normal stress, (2) Mean stress, (3) T- 

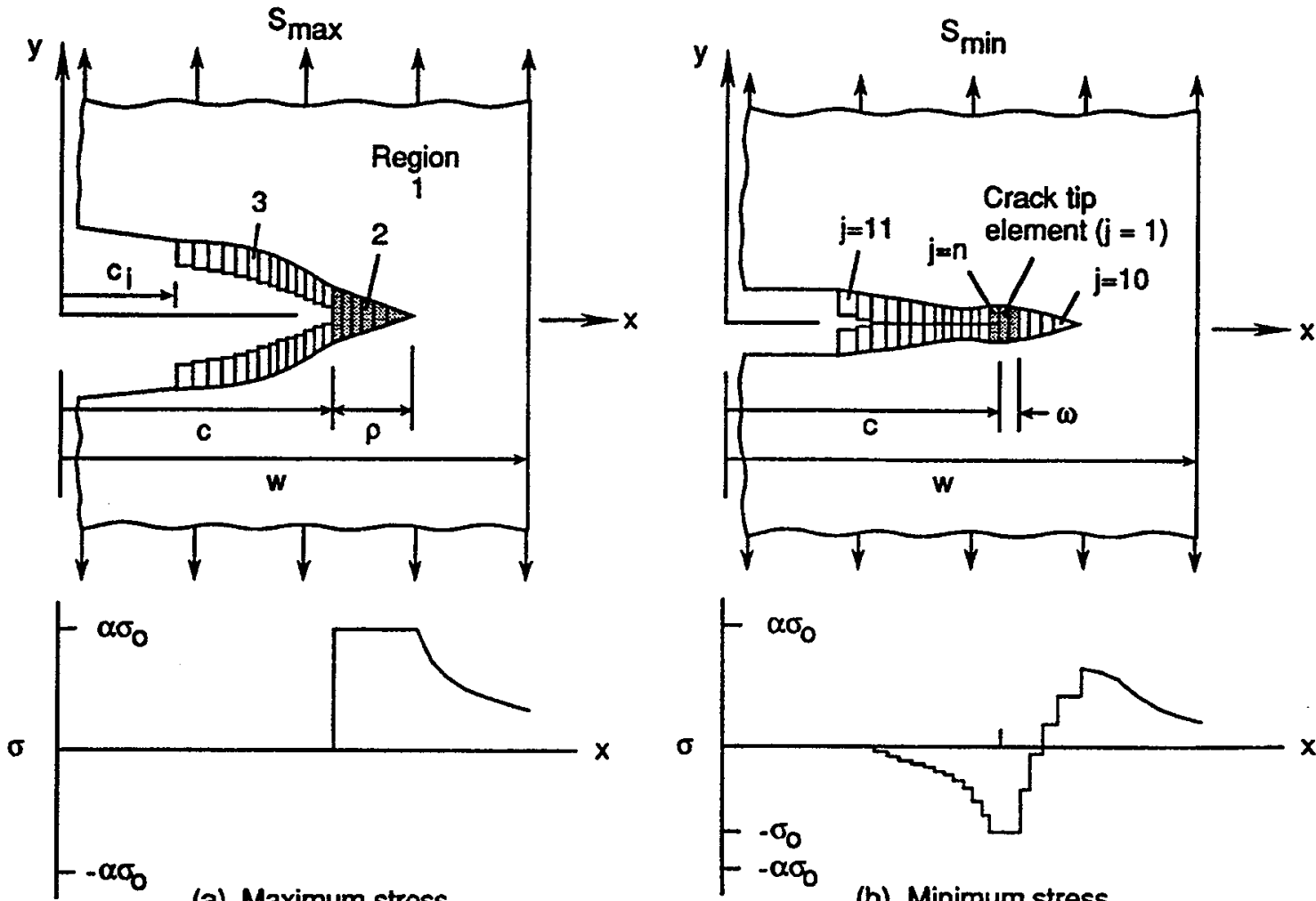

(a) Maximum stress.

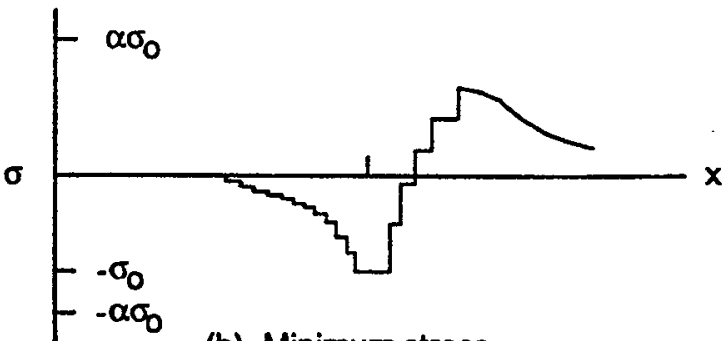

(b) Minimum stress.

FIG. 10-A typical Dugdale or strip-yield model for plasticity-induced closure (after Newman, $1981[$ [II2]).

stress, and (4) Q-stress. In 1960, an elevation of the "normal" stress was used by Irwin [56] in developing equation (4) using only the $\mathrm{K}$ solution. This is similar to the constraint factor used in the modified strip-yield models (see Ref. 112). McClintock [129] and Rice and Tracey [130] considered the influence of the mean stress, $\sigma_{\mathrm{m}}=\left(\sigma_{1}+\sigma_{2}+\sigma_{3}\right) / 3$, on void growth to predict fracture. The mean stress parameter is currently being used in conjunction with threedimensional (3D), elastic-plastic, finite-element analyses to characterize the local constraint at 3D crack fronts, see for example Reference 131 .

In the early 1970's, the fracture community realized that a single parameter, such as K or $\mathrm{J}$, was not adequate in predicting the plastic-zone size and fracture over a wide range of crack lengths, specimen sizes, and loading conditions. At this point, "two-parameter" fracture mechanics was born. The second parameter was "constraint." The characterization of constraint, however, has been expressed in terms of the next term(s) in the series expansion of the elastic or elastic-plastic crack-tip stress fields. In 1975, Larsson and Carlsson [132] demonstrated that the second term, denoted as the T-stress (stress parallel to the crack surfaces), had a significant effect on the shape and size of the plastic zone. The effects of the 
elastic $\mathrm{T}$-stress on $\mathrm{J}$ dominance for an elastic-plastic material under plane-strain conditions was studied by Betegon and Hancock [133] using finite-element analyses. Analytically, Li and Wang [134] developed a procedure to determine the second term in the asymptotic expansion of the crack-tip stress field for a nonlinear material under plane-strain conditions. Similarly, O'Dowd and Shih $[135,136]$ have developed the J-Q field equations to characterize the difference between the HRR stress field and the actual stresses. The Q-stress collectively represents all of the higher order terms for nonlinear material behavior. The J-Q field equations have been developed for plane-strain conditions. An asymptotic analysis that includes more terms for the stress and deformation fields at a crack embedded in a nonlinear material under Mode I and II loading for either plane-stress or plane-strain conditions has been developed by Yang et al. [137, 138]. Chao et al. [138] demonstrated that the first "three" terms in these series expansion $\left(J, A_{2}\right.$, and $\left.A_{3}\right)$ can characterize the stress $\sigma_{i j}$ for a large region around the crack tip for Mode I plane-strain conditions. The third term was subsequently shown to be directly related to the first and second terms, thus two amplitudes, $J$ and $A_{2}$, were sufficient to describe the local stress field.

In 1973, the Two-Parameter Fracture Criterion (TPFC) of Newman $[139,140]$ was developed which used the additional term in the local stress equations for a sharp notch or a crack. The TPFC equation, $\mathrm{K}_{\mathrm{F}}=\mathrm{K}_{\mathrm{Ie}} /\left(1-\mathrm{m} \mathrm{S}_{\mathbf{n}} / \sigma_{\mathrm{u}}\right.$ ), was derived using two approaches. ( $\mathrm{K}_{\mathrm{F}}$ and $\mathrm{m}$ were the two fracture parameters; $\mathrm{K}_{\mathrm{Ie}}$ is the elastic stress-intensity at failure; $\mathrm{S}_{\mathrm{n}}$ is the net-section stress and $\sigma_{\mathbf{u}}$ is the ultimate tensile strength.) In the first approach, the stressconcentration factor for an ellipsoidal cavity, $\mathrm{K}_{\mathrm{T}}=1+2(\mathrm{a} / \rho)^{1 / 2} / \Phi$ from Sadowsky and Sternberg [141], was used with Neuber's equation [6], $\mathrm{K}_{\sigma} \mathrm{K}_{\varepsilon}=\mathrm{K}_{\mathrm{T}}{ }^{2}$, to derive a relation between local elastic-plastic stresses and strains and remote loading. This is similar to the way Kuhn and Figge [142] used the Hardrath-Ohman equation [7] many years earlier. Assuming that fracture occurred when the notch-root stress and strain was equal to the fracture stress and strain, $\sigma_{\mathrm{f}}$ and $\varepsilon_{\mathrm{f}}$, respectively, and that a crack had a critical notch-root radius, $\rho^{*}$, the TPFC equation was derived. The second parameter, $m$, came from the "unity" term in the stressconcentration equation. The second approach [140], used the elastic stress field equation for a crack (eqn.(1)) and Neuber's equation to relate the elastic stresses to the elastic-plastic stresses and strains at a crack tip. In this approach, it was again assumed that fracture occurred at a critical distance, $\mathrm{r}^{*}$, in front of the crack tip when the local stress and strain was equal to the fracture stress and strain, $\sigma_{\mathrm{f}}$ and $\varepsilon_{\mathrm{f}}$. The second parameter, $\mathrm{m}$, came from the next higherorder term in the stress-field expansion. The TPFC has been successfully applied to a large amount of fracture data on two- and three-dimensional crack configuration and materials.

As pointed out by Merkle, in the Fifth Swedlow Lecture [143], "... estimation of constraint effects is best accomplished with three-dimensional analyses." With this in mind, Newman et al. $[144,145]$ conducted 3D elastic-plastic, finite-element analyses on a cracked plate with a wide range in crack lengths, thicknesses, and widths for an elastic-perfectly-plastic material under tension and bending loads. Because the previously discussed crack-closure models require information about constraint (elevation of the normal stress around the crack tip), an average normal stress in the plastically-deformed material normalized by the flow stress 
was evaluated from the $3 \mathrm{D}$ analyses. This normalized average stress was denoted as a global constraint factor, $\alpha_{\mathrm{g}}$. Some typical results of $\alpha_{\mathrm{g}}$ plotted against a normalized $\mathrm{K}$ are shown in Fig. 11 for a thin-sheet material. The symbols show the results from the analyses for various specimen sizes. The upper dashed lines show the results under plane-strain conditions. The global constraint factor was nearly a unique function of the applied $\mathrm{K}$ level. Some slight differences were observed near the plane-stress conditions (high $\mathrm{K}$ levels). These results show that the global constraint factor rapidly drops as the $\mathrm{K}$ level increases (plastic-zone size increases) and approaches a value near the plane-stress limit. The solid line is a simple fit to the results and shows that the constraint-loss regime may be defined by a unique set of $K$ values under monotonic loading. On the basis of some results from cyclic loading and conjecture, the constraint-loss regime may be defined by a unique set of $\Delta \mathrm{K}_{\text {eff }}$ values under cyclic loading. This point will be discussed later.

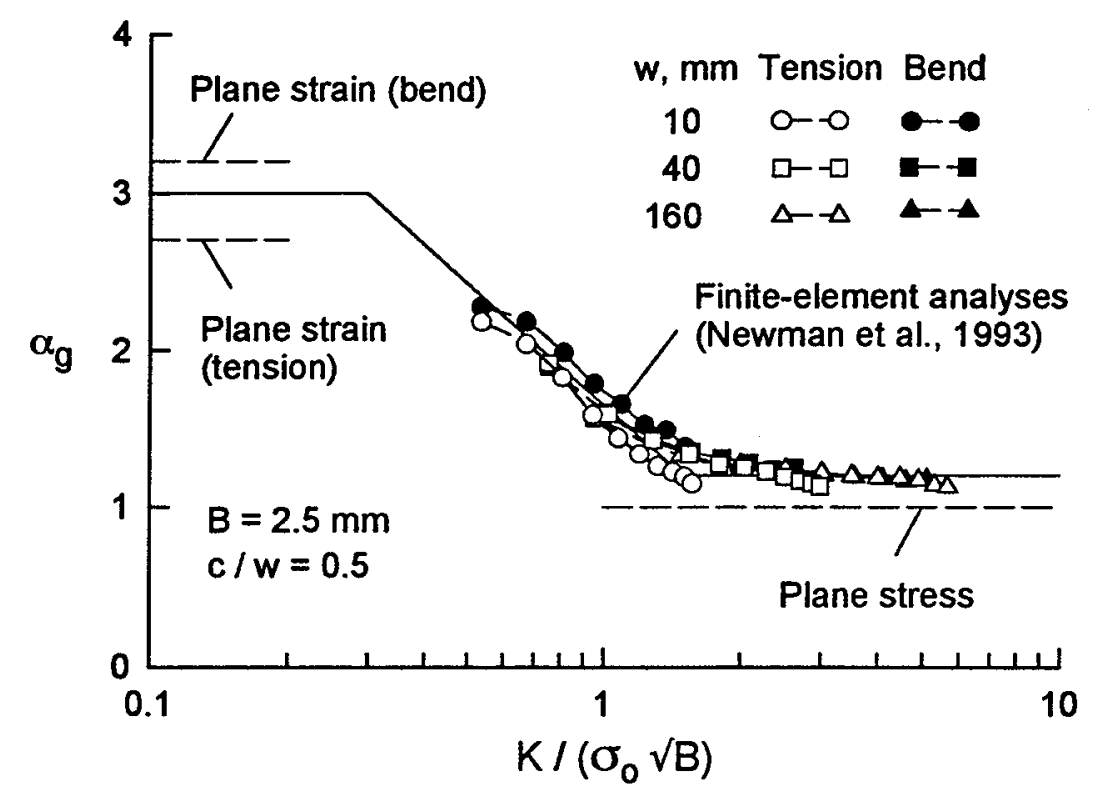

FIG. 11-Constraint variations from three-dimensional finite-element analyses (after Newman et al., 1994 [145]).

\section{CRACK GROWTH RATE RELATIONS}

The number of fatigue-crack growth rate relations in the literature is enormous. But the first such relation was attributed to Head in 1953 [146]. After the Comet accidents [2], which were caused by fatigue cracks growing from windows in the fuselage, the search for a reliable crack-tip parameter and growth rate relation was underway. Table 4 gives a very small list of some crack-growth rate relations that have been proposed since the early 1960 's. This list is a summary of the major relations that are currently being used today in many damage-tolerance 
life-prediction codes. In 1961, Paris et al. [4] made a major step in applying the stress-intensity factor range to fatigue-crack growth. Donaldson and Anderson [147] demonstrated how this new concept could be applied to aircraft components. Very quickly it was found that $\Delta \mathrm{K}$ alone would not correlate fatigue-crack growth rate data for different stress ratios, $R$, and other equations were proposed. Of these, the Forman et al. [148] and Walker [149] equations are commonly used in many life-prediction codes. The next major step in understanding fatiguecrack growth came when Elber [11,33,150] discovered crack closure and proposed that the $\Delta \mathrm{K}_{\text {eff }}$ parameter should control crack growth. Prior to Elber's discovery, Tomkins [15I] was using the BCS (Bilby, Cottrell and Swinden [152]) model to develop a local crack-tip displacement parameter for crack growth. After Rice [9] developed the J-integral, Dowling and Begley $[53,54]$, and others, began to explore the use of the $\Delta \mathrm{J}$ eff parameter for fatigue-crack growth. Similarly, Ogura et al. [153] proposed to use the local cyclic hysteresis energy ( $\left.\mathrm{W}_{\mathrm{eff}}\right)$. The relationship between $\Delta \mathrm{K}$, or any other parameter discussed here, plotted against crack-growth rate does not always fit the simple power laws that have been proposed. Miller and Gallagher [154] found that more accurate life predictions could be made if a table-lookup procedure was used. (The reason that the table-lookup procedure is more accurate will become apparent later.) A number of life prediction codes, such as NASA FLAGRO [155] and FASTRAN-II [156], have adopted this procedure.

TABLE 4--Evolution of some typical crack-growth rate relations.

- Paris, Gomez and Anderson (1961): $d c / d N=C \Delta K^{n}$

- Paris and Erdogan (1963): $\mathrm{dc} / \mathrm{dN}=\mathrm{C} \Delta \mathrm{K}^{\mathrm{n}}\left(\mathrm{K}_{\max }\right)^{\mathrm{m}}$

- Forman, Kearney and Engle (1967): $d c / d N=f\left(\Delta K, R, K_{c}\right)$

- Tomkins (1968): $d c / d N=f(\triangle C T O D)$

- Elber (1970): dc/dN $=C\left(\Delta K_{\text {eff }}\right)^{n}$

- Walker (1970): $\mathrm{dc} / \mathrm{dN}=\mathrm{f}(\Delta \mathrm{K}, \mathrm{R})$

- Dowling and Begley (1976): dc/dN $=\mathrm{C}\left(\Delta \mathrm{J}_{\text {eff }}\right)^{\mathrm{n}}$

- Ogura et al. (1985): $\mathrm{dc} / \mathrm{dN}=\mathrm{f}\left(\mathrm{W}_{\text {eff }}\right)$

- Miller and Gallagher (1981): Table-lookup procedure $\mathrm{dc} / \mathrm{dN}=\mathrm{f}(\Delta \mathrm{K}, \mathrm{R})$

\section{LARGE CRACK GROWTH BEHAVIOR}

This next section will review some observations and present results on the effects of microstructure, environment, and loading on fatigue-crack growth rate behavior. 


\section{Microstructural Effects}

As previously mentioned, fatigue-crack growth rate relations do not necessarily fit a simple power law because of sharp transitions in the $\Delta \mathrm{K}$-rate curves. In 1982, Yoder et al. [157], using data generated by Bucci et al. (1980), began to explain these transitions in terms of microstructural barriers to slip-band transmission, as shown in Fig. 12. The transition to threshold, $T_{1}$, appeared to be controlled by dispersoid spacing (cyclic plastic zone was about the size of the mean free path between dispersoid particles). Similarly, for $T_{2}$ and $T_{3}$, the cyclic plastic zone size appeared to correlate with the subgrain and grain size, respectively. Note that these tests were conducted at an $R$ ratio of 0.33 . Phillips (see Ref. 145) tested 7075-T6 at $R$ ratios of $-1,0$ and 0.5 and found that these transitions were at different $\Delta K$ levels for each $R$ ratio, but that each transition occurred at nearly the same crack-growth rate. Wanhill (Annex $A$ in Ref. 17) found similar transitions in 2024-T3 aluminum alloy and concluded that the transitions were controlled by the "effective cyclic plastic zones" based on $\Delta \mathrm{K}_{\text {eff }}$ instead of the cyclic plastic zones computed from $\Delta \mathrm{K}$. Thus, the transitions in the two alloys appear to be controlled by $\Delta \mathrm{K}_{\text {eff }}$ in laboratory air because the transitions occur at about the same rate.

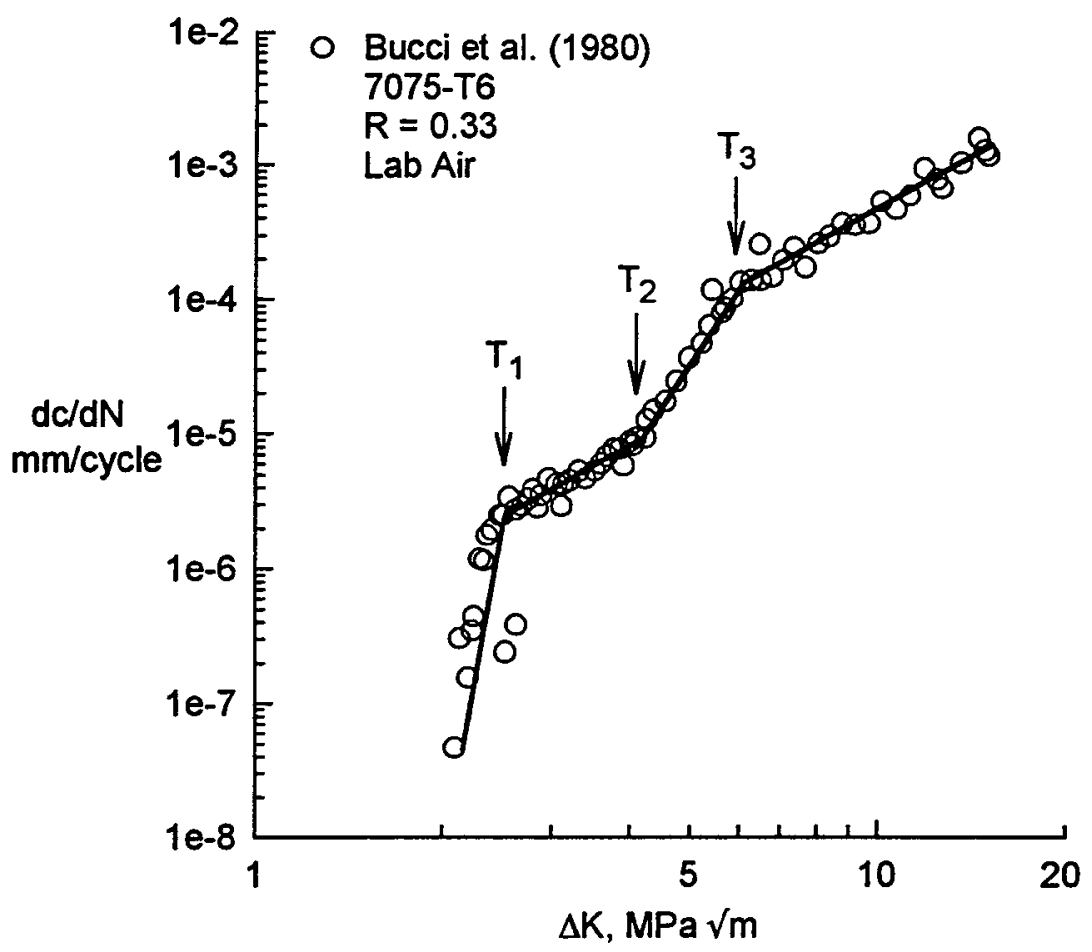

FIG. 12--Microstructural control of fatigue-crack growth (after Yoder et al., 1982 [157]). 


\section{Environmental Effects}

Piascik and Gangloff [158] found that these transitions were affected by the environment in crack-growth rate tests on a 2090 aluminum-lithium alloy. Fig. 13 shows tests results in (1) moist air or water vapor, (2) $\mathrm{NaCl}$ solution, and (3) Oxygen, helium or vacuum. Test results in each category fell along a particular $\Delta \mathrm{K}$-rate relation. The results in moist air or water vapor show a similar characteristic as exhibited by the 7075 alloy in laboratory air (Fig. 12), that is, the sharp transitions at $T_{1}$ and $T_{2}$. But tests under the salt solution, eliminated the $T_{2}$ transition and moved the $T_{1}$ transition to a different values of $\Delta K$. Under the inert environments, the transitions did not develop. Piascik and Gangloff attributed these behaviors at low crack-growth rates to fracture mode changes from cracking on the $\{100\}$ plane in the salt solution to slip-band cracking in the inert environments.

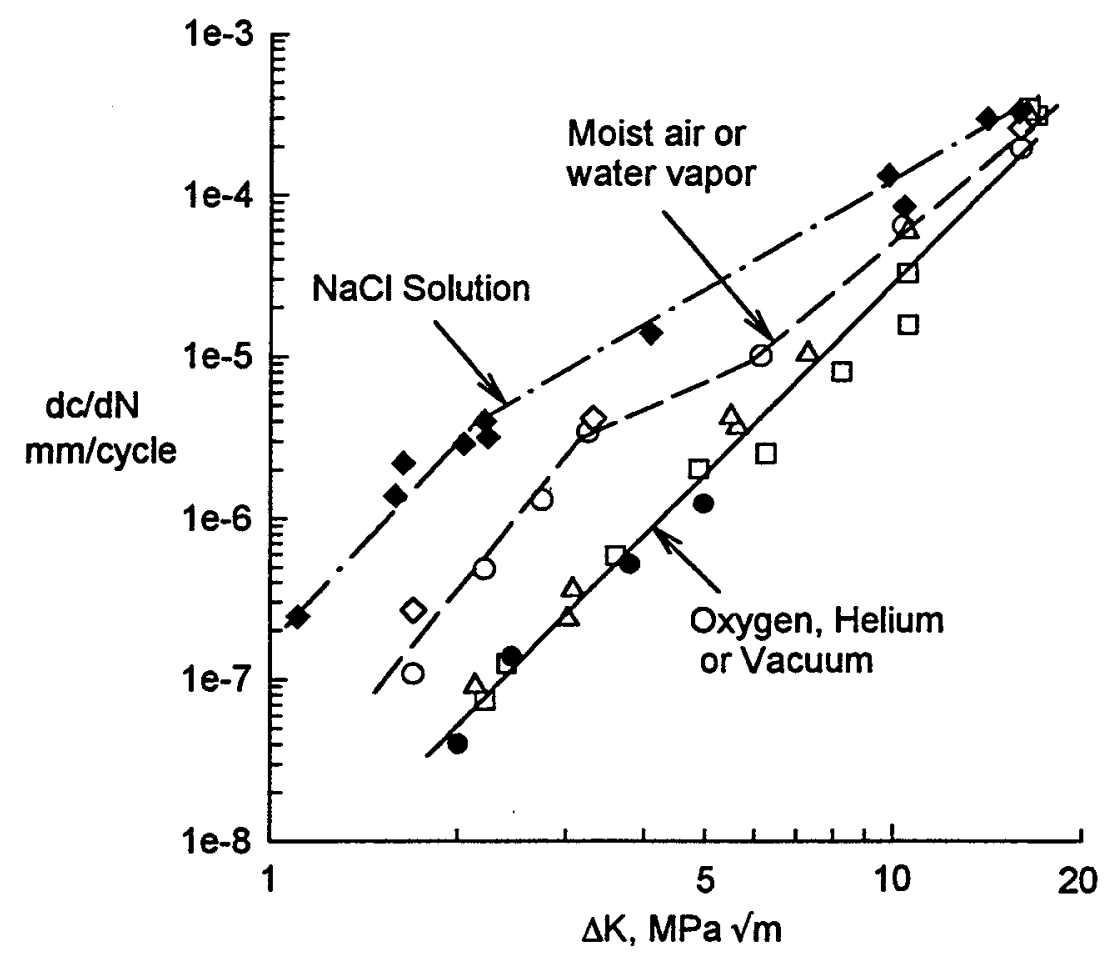

FIG. 13--Environmental fatigue-crack growth in aluminum-lithium alloy (after Piascik and Gangloff, 1993 [158]).

Results from Petit and Henaff $[159,160]$, as shown in Fig. 14, demonstrate the intrinsic behavior of crack growth under the various fracture modes, Stage I, Stage II and Stage I-Like for a wide variety of materials and $R$ ratios tested in high vacuum. When the Stage II crackgrowth rate data is plotted against $\Delta \mathrm{K}_{\mathrm{eff}}$ normalized by the elastic modulus $(\mathrm{E})$, all materials (aluminum alloys, aluminum-lithium alloys, steels and TA6V) fall along a unique relation. Similar results are shown for the Stage I and Stage I-Like behaviors. These results help explain 
why the fracture mode changes can produce transitions in the $\Delta \mathrm{K}$-rate relations. These results also demonstrate how new, metallic materials can be developed to have improved damagetolerance properties. With many engineering metals falling together on a $\Delta \mathrm{K}_{\mathrm{eff}} / \mathrm{E}$ plot, one way to improve the material is to produce a material that would have a large amount of closure either due to plasticity, roughness, or some other closure mechanism.

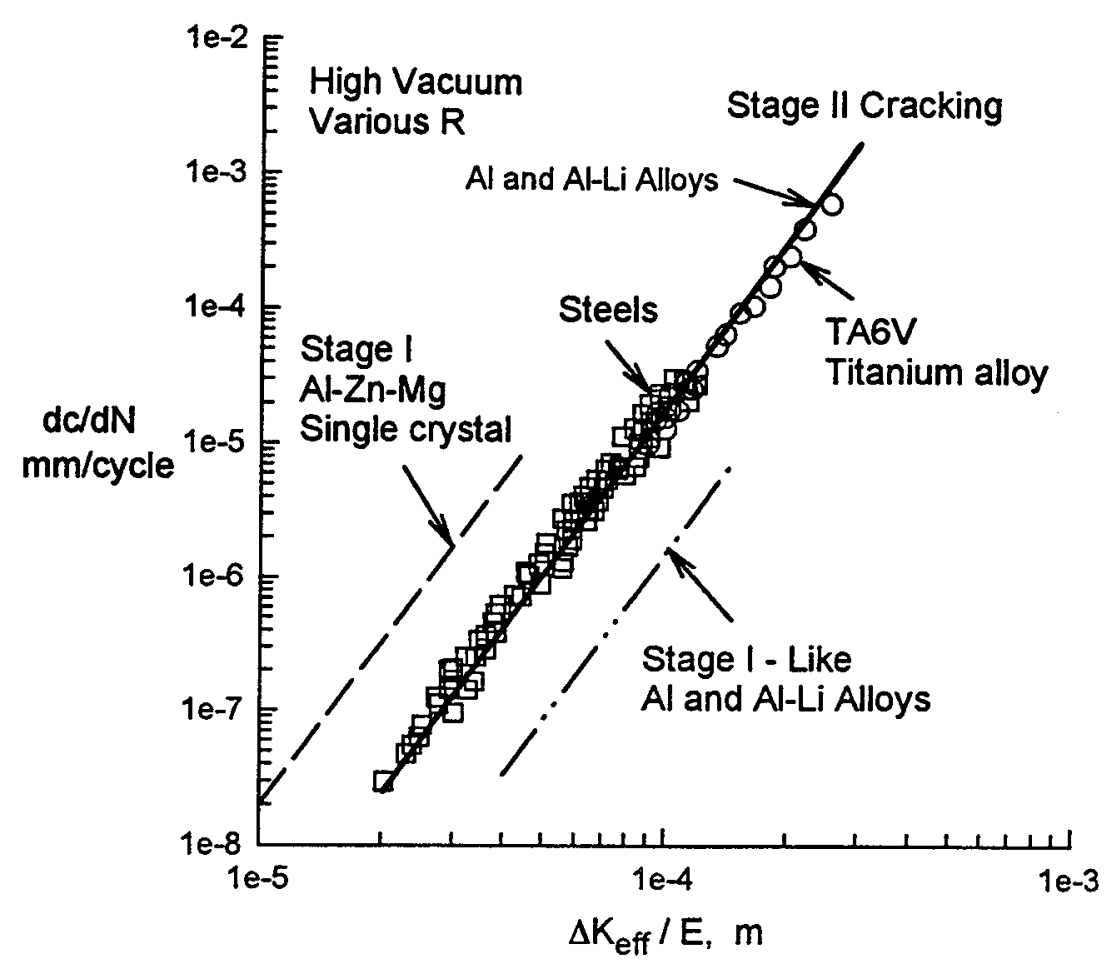

FIG. 14-Intrinsic fatigue crack growth for various material at high vacuum (after Petit and Henaff, 1991-93 [159,160]).

\section{Loading Effects}

Large-Crack Threshold--Because many of the comparisons between the growth of small and large cracks have been made in the near-threshold regime for large cracks, it is important to know whether the large-crack threshold is a material property or is caused by the load-reduction procedure. Several investigators have experimentally or numerically shown (see Ref. 161) that the stress-intensity factor threshold under load-reduction schemes can be partly explained by the crack-closure behavior. Some typical results on an aluminum alloy are shown in Fig. 15. Minakawa and McEvily [162] conducted a threshold test on a compact specimen and measured the crack-opening loads as the $\Delta K$ level approached $\Delta \mathrm{K}_{\mathrm{th}}$. The crack-opening loads were determined from a displacement gage at the crack mouth. For high $\Delta K$ levels, the $P_{0} / P_{\max }$ values ranged from 0.15 to 
0.35. The horizontal line is the calculated $P_{o} / P_{\max }$ ratio from Newman's crack-closure model [112] under constant-amplitude loading with plane-strain conditions $(\alpha=3)$. The calculated ratios agreed fairly well with the experimental values. As $\Delta \mathrm{K}$ approached $\Delta \mathrm{K}_{\text {th }}$, the $\mathbf{P}_{\mathbf{d}} / \mathbf{P}_{\max }$ ratio rapidly rose and the ratio was nearly unity at threshold. Thus, the rise in crack-opening load explains why the threshold developed. But what caused the rise in crack-opening loads? A number of suggestions have been advanced to explain this behavior. Among these are the mismatch of crack-surface features observed by Walker and Beevers [34] in a titanium alloy; the corrosion product formation on the crack surfaces, as observed by Paris et al. [37]; the variation in the mode of crack growth with stress-intensity factor level as reported by Minakawa and McEvily [162]; and the plastic wake caused by the load-reduction procedure [161]. The usefulness of the large-crack threshold data for small-crack growth is in question, if the threshold development is caused by the activation of different fracture modes, such as roughness-induced closure, and these mechanisms are not activated for small cracks. If the large-crack threshold is affected by the load-reduction procedure, then the overall usefulness of $\Delta \mathrm{K}_{\text {th }}$ for largecrack-growth behavior under variable-amplitude loading is also questionable.

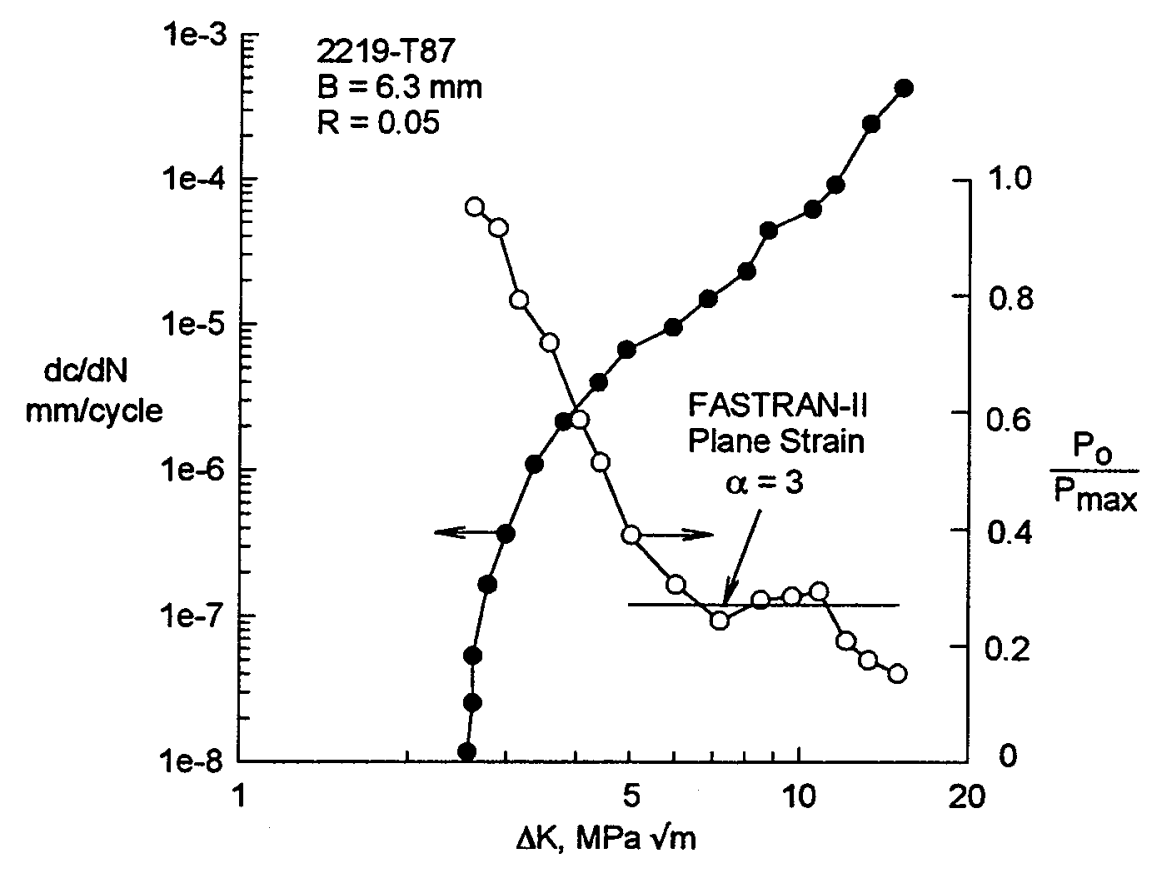

FIG. 15--Experimental crack-growth rates and opening levels near large-crack threshold (modified after Minakawa and McEvily, 1981 [161]).

Transition from Tensile-to-Shear Mode Crack Growth--The crack-growth regime where a crack grows from flat (tensile fracture) to slant (shear fracture), as shown in Fig. 16 , is important to defining the constraint-loss regime from plane strain to plane stress. As 
observed by Schijve [26], the end of transition from flat-to-slant crack growth appears to occur at the same fatigue crack-growth rate, independent of the stress ratio. Newman et al. [163] used this observation to control the constraint-loss regime in the analytical crackclosure model. Because the crack-closure concept is able to collapse crack-growth rate

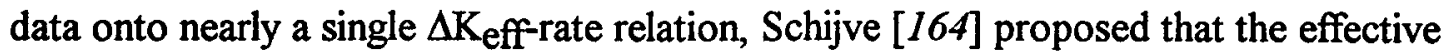
stress-intensity factor should control the transition from flat-to-slant crack growth. To develop a simple estimate for the transitional region, Newman [106] proposed that the transition to complete slant crack growth occurs when the effective cyclic plastic-zone size calculated from $\Delta \mathrm{K}_{\text {eff }}$ is a certain percentage of the sheet thickness. This relation is

$$
\mu=\left(\Delta \mathrm{K}_{\mathrm{eff}}\right) \mathrm{T} /\left(\sigma_{\mathrm{o}} \sqrt{\mathrm{B}}\right)
$$

where $\sigma_{0}$ is the flow stress and B is the sheet thickness. Using transitional data from the literature, the transitional coefficient $(\mu)$ is plotted against sheet thickness in Fig. 17. Although considerable scatter is evident in the data, the general trend is for $\mu$ to be about 0.5 for 1 to $6 \mathrm{~mm}$-thick material. While the $\Delta \mathrm{K}_{\text {eff }}$ at the end of transition is a function of specimen thickness, Wilhem [165] suggested that the beginning of the shear-lip development for aluminum and titanium alloys may be independent of specimen thickness. This is reasonable, considering that the material at the free surface is in a state of plane stress, regardless of thickness.

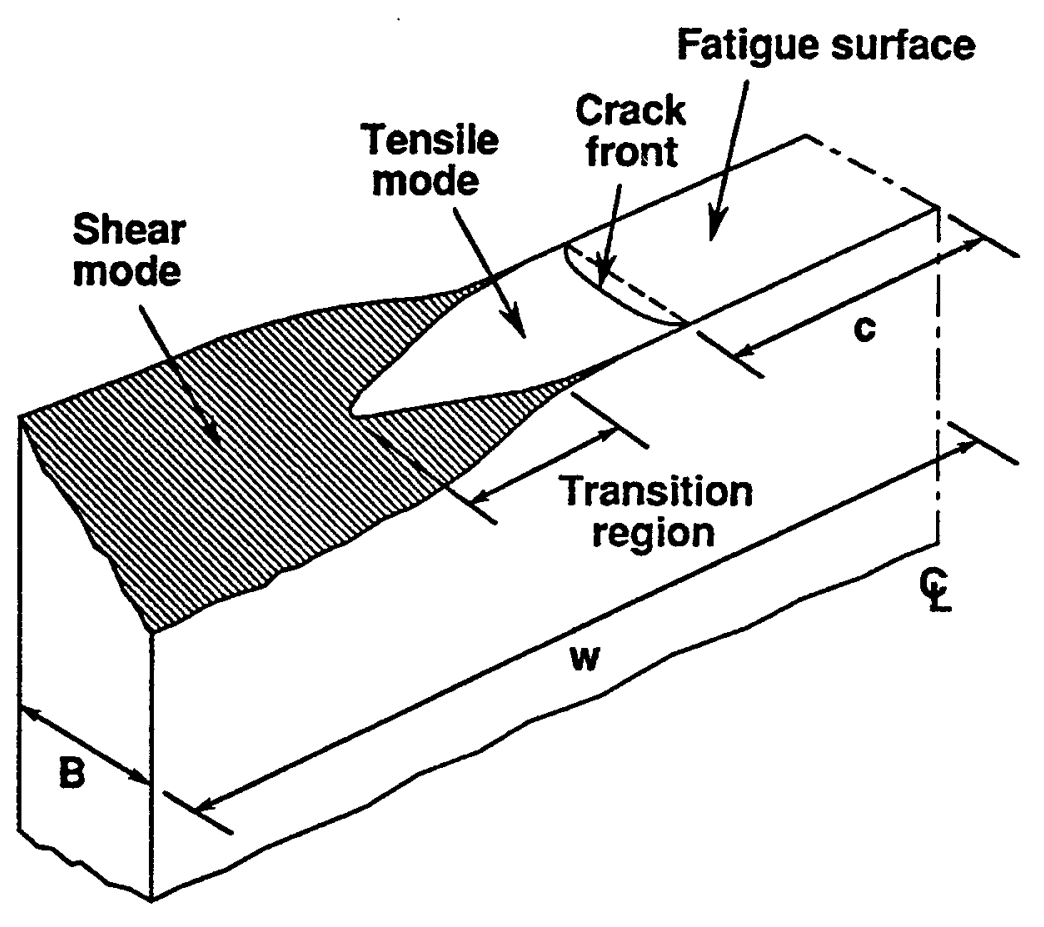

FIG. 16--Flat-to-slant fatigue-crack growth in metallic materials. 


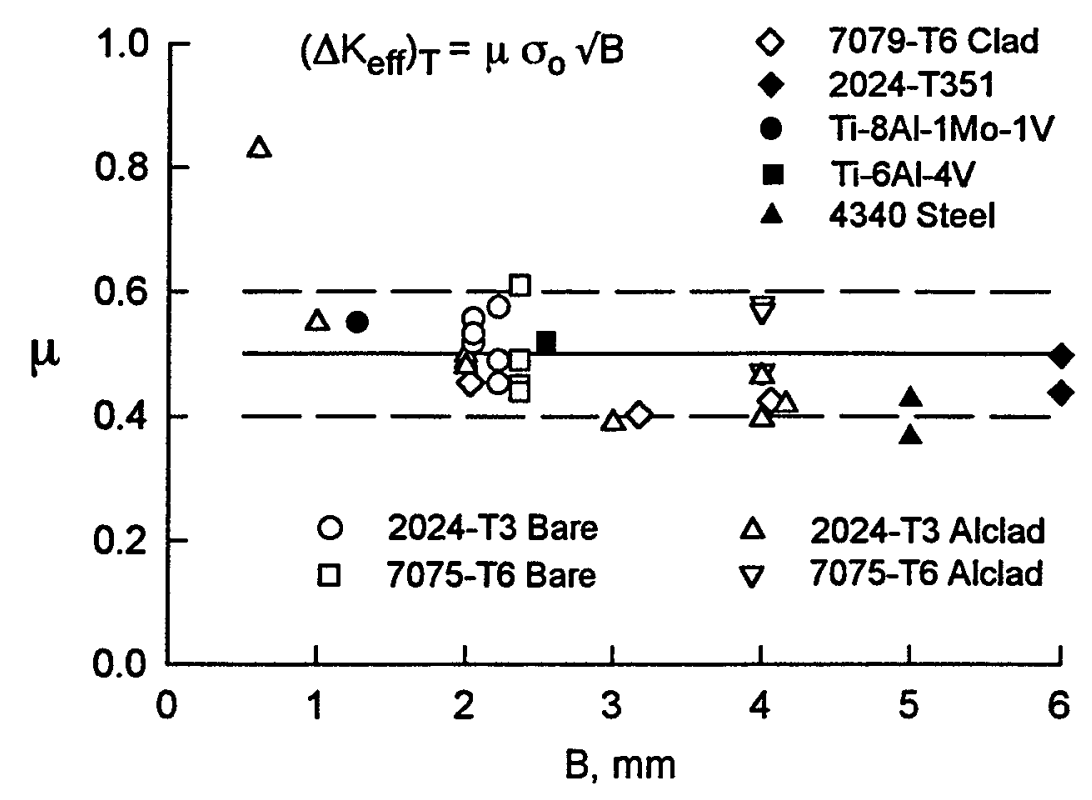

FIG. 17--Controlling parameter for flat-to-slant fatigue-crack growth (after Newman, $1992[106])$.

Constant-Amplitude Loading--In 1969, Hudson [166] produced fatigue-crackgrowth-rate data for 2024-T3 and 7075-T6 aluminum alloy sheet over a wide range of stress ratios $(R=-1$ to 0.8$)$ and stress-intensity factor ranges. Later, Phillips [145, 167] generated crack-growth data in the near-threshold regime for the same alloys; and Dubensky [168] conducted tests at extremely high remote stress levels (0.6 to 1.0 times the yield stress of the material). These tests produced crack-growth-rate data over 8orders of magnitude in rates! These types of tests and data are needed to obtain the baseline crack-growth-rate relations that are needed to predict crack growth under variable-amplitude and aircraft spectrum loading, as will be discussed later.

Typical fatigue-crack growth rate data on 7075-T6 aluminum alloy sheet for various $R$ ratios [20] and analyzed with Newman's closure model equations [89] are shown in Fig. 18. On the basis of $\Delta \mathrm{K}_{\mathrm{eff}}$, the data collapsed into a narrow band with several changes in slope (transitions) occurring at about the same growth rate. For these calculations, a constraint factor $(\alpha)$ of 1.8 was selected for rates less than $7 \mathrm{E}-4 \mathrm{~mm} /$ cycle and $\alpha$ equal to 1.2 for rates greater than $7 \mathrm{E}-3 \mathrm{~mm} /$ cycle. The vertical dash line shows the calculation of ( $\Delta \mathrm{K}_{\mathrm{eff}} \mathrm{T}$ from equation (8) with $\mu=0.5$. The $\mathrm{T}_{4}$ location (defined herein) shows a sharp transition in the constraint-loss regime. The solid line is the baseline relation. In the low crack-growth rate regime, the large-crack threshold data has been neglected. The baseline relation near the large-crack threshold is an estimate based on small-crack data [20]. 


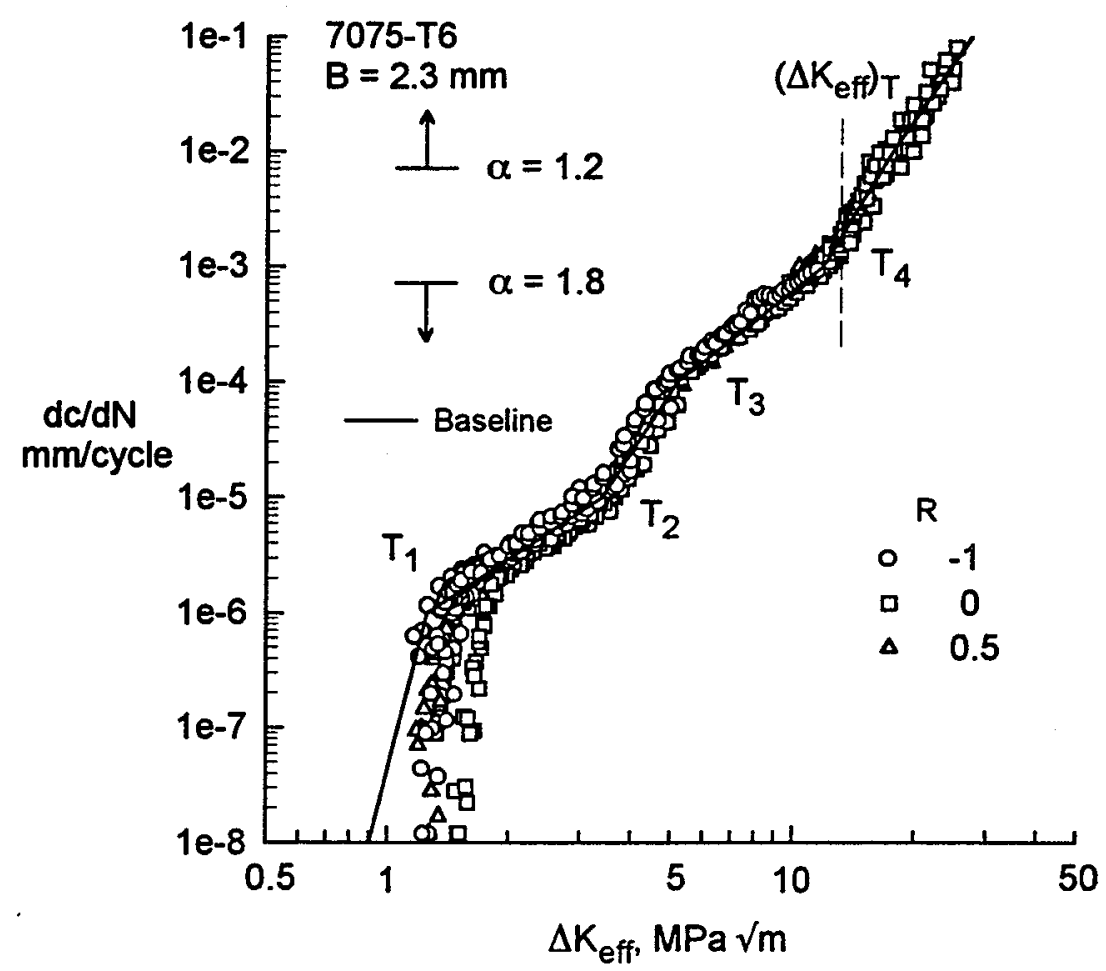

FIG. 18--Effective stress-intensity factor against crack-growth rate for an aluminum alloy (after Newman et al., 1994 [20]).

Spectrum Loading--Wanhill $[169,170]$ conducted spectrum crack-growth tests on middle-crack tension specimens made of 2024-T3 Alclad material $(B=3.1 \mathrm{~mm})$. Tests were conducted under the TWIST (transport wing spectrum) clipped at Level III with a mean flight stress of $\mathrm{S}_{\mathrm{mf}}=70 \mathrm{MPa}$. Fig. 19 shows a comparison of test results and calculated results from Newman's closure model [112] with the constraint-loss regime ( $\alpha$

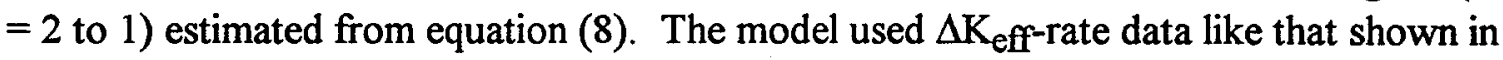
Fig. 18, but for the 2024-T3 alloy. To illustrate why the constraint-loss regime is necessary, example calculations were made for constant constraint conditions of either $\alpha=$ 1 or 2 (dashed curves). The model with a low constraint condition $(\alpha=1)$ predicted much longer lives than the tests, whereas the model with the high constraint predicted much shorter lives than the tests. Thus, the correct constraint-loss regime is required to predict fatigue-crack growth under aircraft spectrum loading in thin-sheet materials.

\section{SMALL CRACK GROWTH BEHAVIOR}

The observation that small or short fatigue cracks can: (1) grow more rapid than those predicted by linear-elastic fracture mechanics (LEFM) based on large-crack data, and (2) grow at $\Delta \mathrm{K}$ levels well below the large-crack threshold, has attracted considerable 


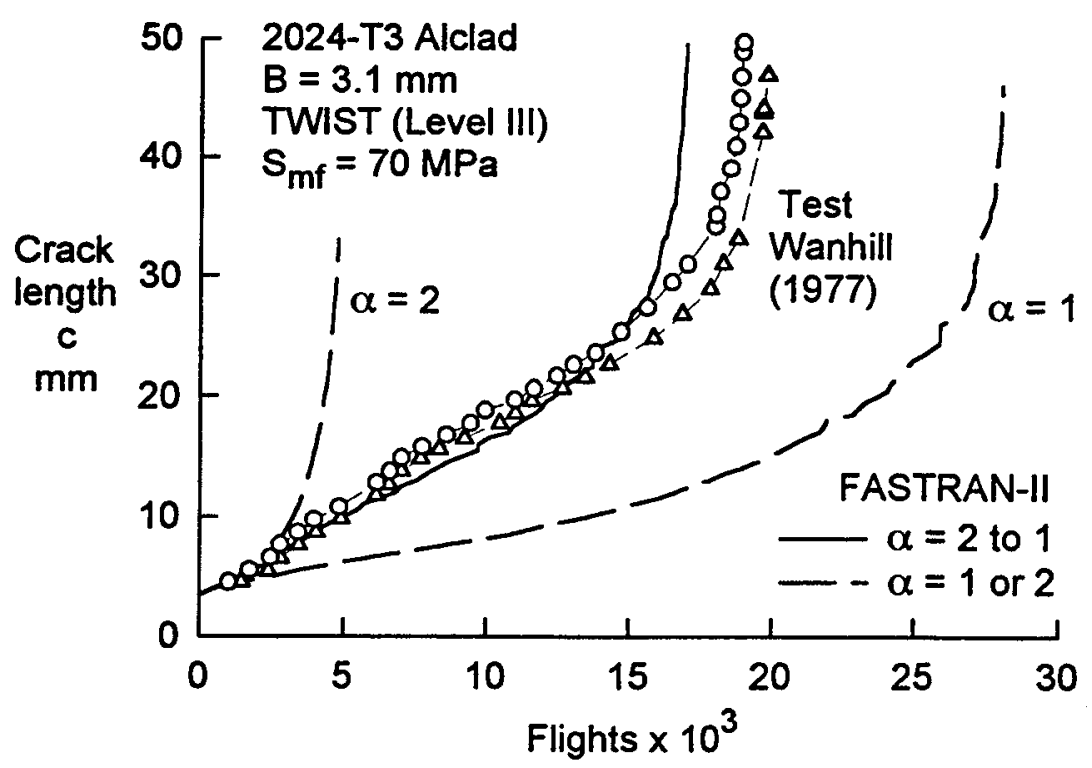

FIG. 19--Experimental and calculated crack length against flights for an aluminum alloy (after Newman, 1992 [106]).

attention in the last two decades [12-2I]. Some consensus is emerging on crack dimensions, mechanisms, and possible methods to correlate and to predict small-crack behavior. A useful classification of small cracks has been made by Ritchie and Lankford [171] and these are summarized in Table 5. Naturally-occurring (three-dimensional) small cracks, often approaching microstructural dimensions, are largely affected by crack shape (surface or corner cracks), enhanced crack-tip plastic strains due to micro-plasticity, local arrest at grain boundaries, and the lack of crack closure in the early stages of growth. Whereas, two-dimensional short cracks, about $100 \mu \mathrm{m}$ or greater, are through-thickness cracks which have been created artificially be removing the wake of material from large through cracks. Their behavior appears to be controlled by the plastic-wake history left by the large-crack growth process and the crack-growth rates are averaged over many grains through the thickness.

Over the last two decades, in the treatment of microstructurally-, mechanically-, and physically-small cracks, two basic approaches have emerged to explain the rapid growth and deceleration of small cracks when compared to large-crack growth behavior. The first is characterized by "grain-boundary" blocking and consideration of microstructural effects on small-crack growth rates (see for example Refs. 21 and 172). The second is a "continuum mechanics" approach accounting for the effects of material nonlinearity on the crack-tip driving force and crack-closure transients (see for example Refs. 161 and 173). 
TABLE 5--Classes of small-fatigue cracks, dimensions, responsible mechanisms and potential crack-tip parameters (modified after Ritchie and Lankford, 1986 [171]).

\begin{tabular}{|c|c|c|c|}
\hline Types of Small Cracks & Dimension & Mechanisms & Parameters \\
\hline Microstructurally-small & $\begin{aligned} a & <d_{g}{ }^{(a)} \\
2 c & <5 \text { to } 10 d_{g}\end{aligned}$ & $\begin{array}{l}\text { Crack-tip shielding } \\
\text { enhanced } \Delta \varepsilon_{\mathrm{p}} \\
\text { Crack shape }\end{array}$ & $\begin{array}{l}\text { Probabilistic } \\
\text { approach }\end{array}$ \\
\hline Mechanically-small & $a<r_{y}{ }^{(b)}$ & $\begin{array}{l}\text { Excessive (active) } \\
\text { plasticity }\end{array}$ & $\begin{array}{l}\Delta \mathrm{J}, \Delta \mathrm{CTOD} \\
\left(\Delta \mathrm{K}_{\mathrm{p}}\right)\end{array}$ \\
\hline Physically-small & $\mathrm{a}<1 \mathrm{~mm}$ & $\begin{array}{l}\text { Crack-tip shielding } \\
\text { (crack closure) }\end{array}$ & $\Delta \mathrm{K}_{\mathrm{eff}}$ \\
\hline Chemically-small & $\begin{array}{l}\text { up to } \cong 10 \mathrm{~mm} \\
\text { (c) }\end{array}$ & $\begin{array}{l}\text { Local crack tip } \\
\text { environment }\end{array}$ & \\
\hline
\end{tabular}

(a) $d_{g}$ is critical microstructural dimension, such as grain size; a is surface-crack depth and $2 \mathrm{c}$ is surface-crack length

(b) $r_{y}$ is plastic-zone size or plastic field of notch

(c) critical size is a function of frequency and reaction kinetics

The microstructural barrier model, developed by Miller and co-workers [15, 172], was conceived to separate regimes of "microstructurally-small" cracks and "physicallysmall" cracks. The regime of microstructurally-small cracks (MSC) occurs when crack lengths are less than a dominant microstructural barrier, such as the grain size. Various researchers consider this regime to be synonymous with growth of a crack across a single grain or several grain diameters. For example, a crack may initiate at an inclusion particle on a grain boundary, propagate, slow down, and stop at the next grain boundary. With further cycling, or if the stress level is increased, this barrier can be overcome and the crack will propagate to the next barrier. Several different microstructural barriers to crack growth may exist in a single material because of material anisotropy and texture. The physically-small crack (PSC) regime is defined for crack lengths greater than the spacing of these dominant barriers. Miller [172] suggests that the complexities near microstructural barriers in the MSC and PSC regimes hinder theoretical analyses of small-crack growth behavior based on LEFM parameters and he emphasizes the development of empirical equations, based on extensive test data, to determine constants in these relations. However, progress has been made in the analyses of cracks growing from inclusions (see for example Ref. 174) and interacting with grain boundaries [113, 116]. These analyses may be useful in developing the LEFM relations for cracks in complex microstructures. 
As shown in Fig. 20, small-crack initiation and growth is a three-dimensional process with cracks in the depth, a, and length, $c$, directions interacting with the grain boundaries at different times in their cyclic history. Whereas, an observed crack in the length direction may have decelerated at or near a grain boundary, the crack depth may still be growing. As the crack grows in the depth direction, the rise in the crack-driving force at the c-location contributes to the crack penetrating that barrier. As the cracks become longer, the influence of grain boundaries become less as the crack front begins to average behavior over more grains. Small-crack growth deceleration may or may not occur depending upon the orientation of the adjacent grains [21]. A probabilistic analysis would be required to assess the influence of the variability of the grain structure on crackgrowth rate properties. From an engineering standpoint, however, a weak-link or worst case scenario of grain orientation may provide a conservative estimate for the growth of small cracks through a complex microstructure. This is the basis for the continuum mechanics approach.

It has been argued that the calculation of $\Delta \mathrm{K}$ for a small crack growing from an inclusion could be in error (Schijve [175]). For example, if crack initiation occurs at a subsurface inclusion with subsequent breakthrough to the surface, a considerable elevation
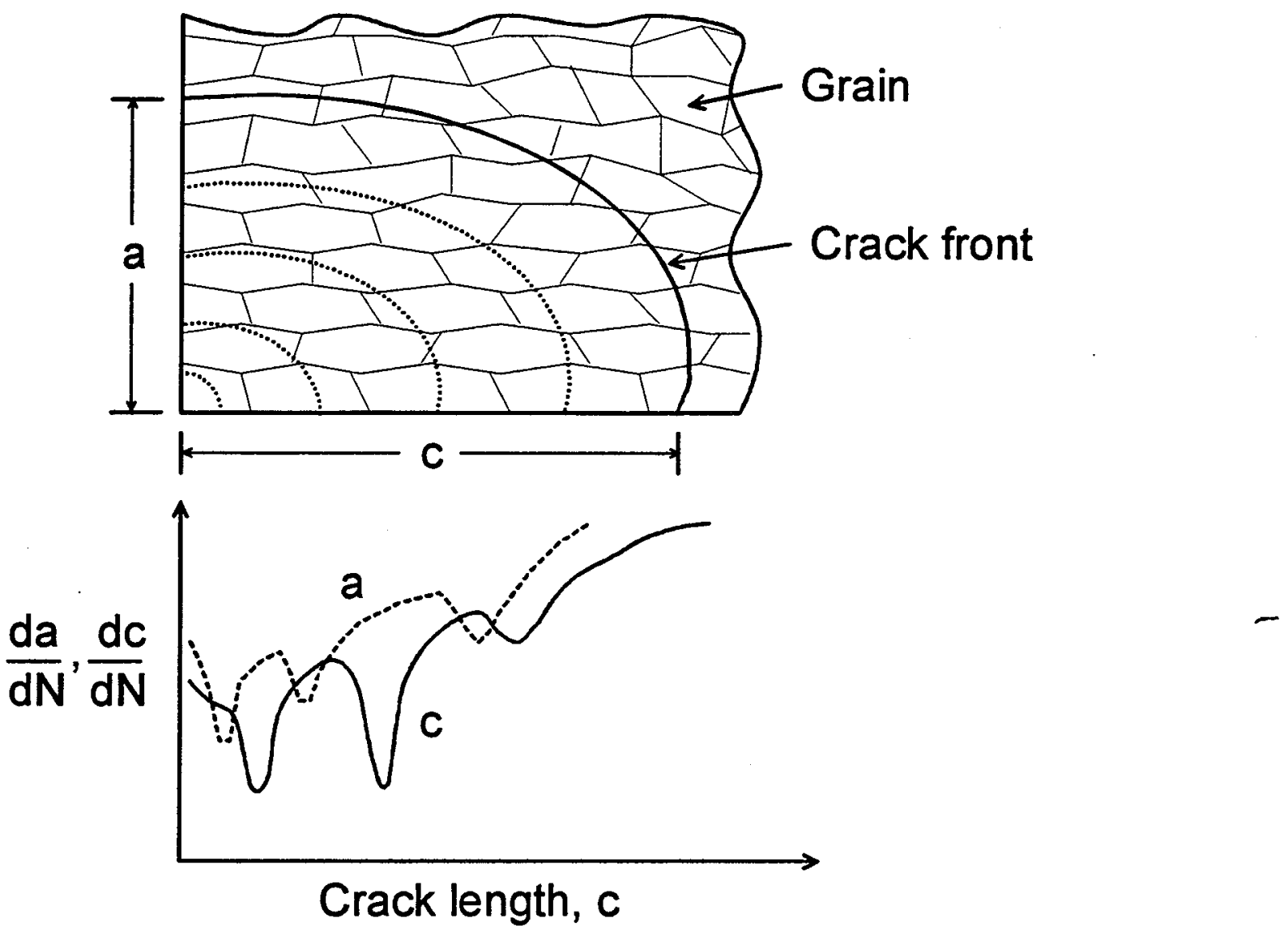

FIG. 20--Surface crack growth and an influence of grain boundaries. 
in $\Delta \mathrm{K}$ is possible over that calculated from surface observations. Although the use of $\Delta \mathrm{K}$ to characterize the growth of small cracks has proved to be convenient, its universal application has been viewed with some skepticism. Despite the above qualifications, research work on the growth of naturally-initiated small cracks, notably by Lankford [21, 176] and AGARD studies [17, 18], has demonstrated the usefulness of the $\Delta \mathrm{K}$ concept.

One of the leading continuum mechanics approaches to small-crack growth is that of Newman et al. [161, 163]. The crack-closure transient (or more correctly the lack of closure in the early stages of growth) has long been suspected as a leading reason for the small-crack effect. The Newman crack-closure model [112] has demonstrated the capability to model small-crack growth behavior in a wide variety of materials and loading conditions [161]. Difficulties still exist for large-scale plastic deformations at holes or notches but these are problems that can be treated with advanced continuum mechanics concepts. In the remaining sections, the application of the Newman model to predict or calculate fatigue life based solely on crack propagation will be reviewed.

Earlier work by Pearson [12] on fatigue-crack initiation and growth of small cracks from inclusion particles in two aluminum alloys (BS L65 and DTD 5050) set the stage for the development of small-crack theory. His results are shown in Fig. 21(a), as the dashed curve, along with additional small-crack data from Lankford [2I] on 7075-T6 aluminum alloy. Pearson concluded that cracks of about the size of the average grain size, grew several times faster than large cracks at nominally identical $\Delta \mathrm{K}$ values. The open symbols and dash-dot curve show the large-crack data and the development of the large-crack threshold at about 3 to $4 \mathrm{MPa} \sqrt{\mathrm{m}}$. The solid symbols show the typical small-crack behavior with growth at $\Delta \mathrm{K}$ levels as low as $1.5 \mathrm{MPa} V_{\mathrm{m}}$. The other solid curves show the behavior measured on other small cracks. Some general observations, by Lankford [21], were that the minimum in $\mathrm{da} / \mathrm{dN}$ occurred when the crack depth, a, was about the minimum dimension of the pancake grain (subsurface grain boundary, as shown in Fig. 20) and that the magnitude of the lower rates was controlled by the degree of micro-plasticity in the next grain penetrated by the crack. If the next grain is oriented like the first, then no deceleration will occur, as indicated by the uppermost small-crack curves in Fig. 21(a).

At this stage, it would be of interest to compare the test results from Pearson and Lankford with the small-crack growth predictions made from a continuum-mechanics model based on crack closure [150]. The $\Delta \mathrm{K}_{\text {eff-rate relation used in the closure model for }}$ the 7075-T6 alloy was generated in Ref. 20 and the relation is shown in Fig. 21(b) as the dotted lines. These results were generated from large-crack data for rates greater than about $2 \mathrm{E}-6 \mathrm{~mm} /$ cycle. The results are quite different from those shown for the PearsonLankford large-crack data in that the $T_{2}$ transition (at about $1 \mathrm{E}-5 \mathrm{~mm} / \mathrm{cycle}$ ) did not appear in their data. The lower section of the $\Delta \mathrm{K}_{\text {eff-rate relation (below } 2 \mathrm{E}-6 \mathrm{~mm} / \text { cycle) }}$ was estimated on the basis of small-crack data, also generated in Ref. 20. Because small cracks are assumed to be fully open on the first cycle, the $\Delta \mathrm{K}_{\text {eff }}$ rate relation is the starting point for small-crack analysis. The results of an analysis of the test specimen used by Lankford is shown by the heavy solid curve. The initial defect was selected as a $10 \mu \mathrm{m}$ radius semi-circular crack, so that the $2 \mathrm{a}$ dimension (on the surface) would be $20 \mu \mathrm{m}$. 


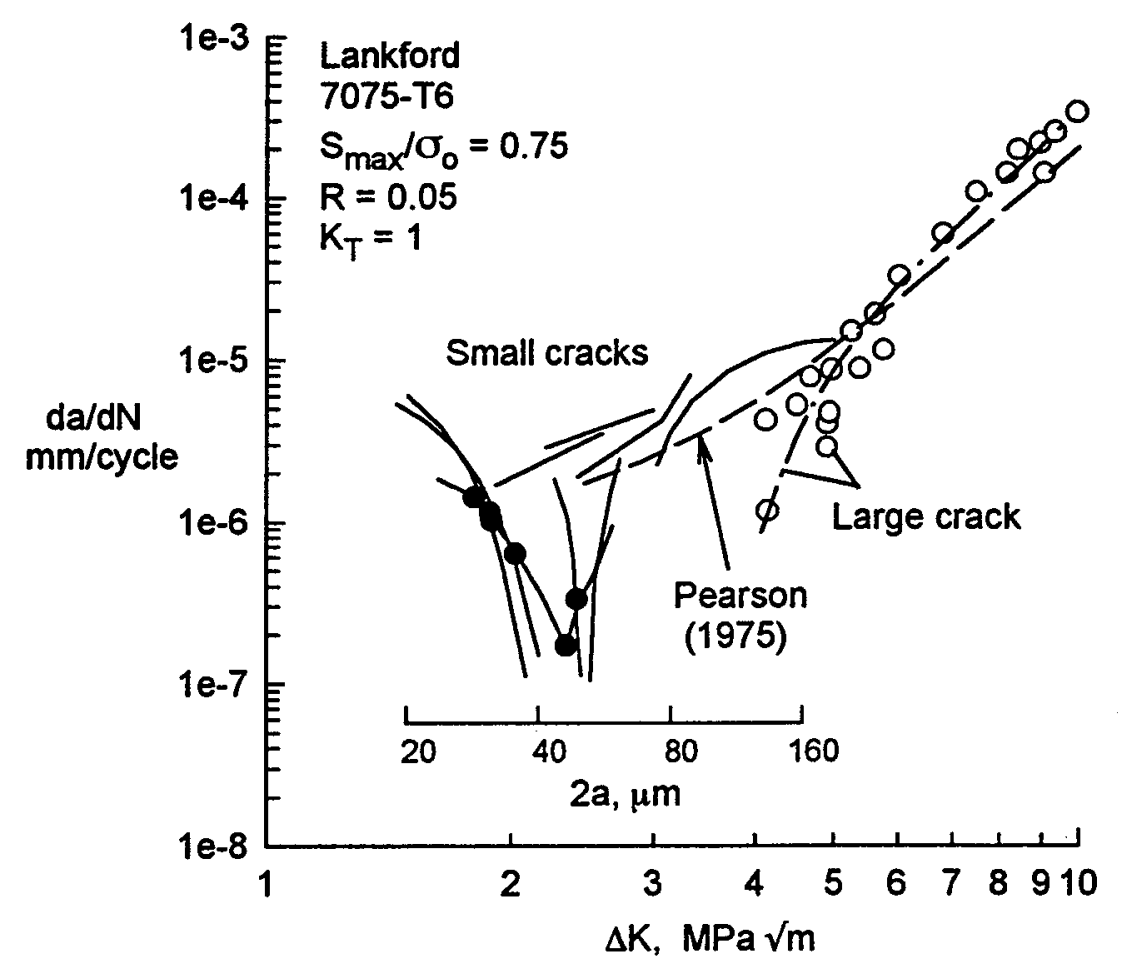

FIG. 21(a)-Measured and calculated small-crack growth in an aluminum alloy (after Lankford, 1982 [2I]).

As the small crack grows, the closure level increases much faster than the $\Delta \mathrm{K}$ level and a rapid decrease in rates is calculated. This rapid drop is a combination of the closure transient and the sharp change in slope at the $T_{1}$ location (at about $1 \mathrm{E}-6 \mathrm{~mm} / \mathrm{cycle}$ ). At about $30 \mu \mathrm{m}$, the crack-opening stresses have nearly stabilized and the effects of plasticity on the crack-driving force is quite small considering that the applied stress was 0.75 times the flow stress (see Fig. 6 in Ref. 63). The predicted small-crack results are in excellent agreement with Pearson's data and agree with Lankford's data which do not exhibit a grain-boundary influence. Interestingly, the small-crack analysis shows a single dip in the small-crack curve, similar to the "single" dip observed in some of Lankford's small-crack data. Would the grain-boundary interaction always occur at the same crack length ( 40 $\mu \mathrm{m})$ ? Why aren't there other dips, or small indications of a dip, in the rate curve at 80 , 120 or $160 \mu \mathrm{m}$ ? Further study is needed to help resolve these issues, but the fatigue life, or at least a lower bound fatigue life, can be calculated from continuum-mechanics concepts. The following sections will review the use of Small-Crack Theory to predict fatigue life for notch specimens under various load histories. 


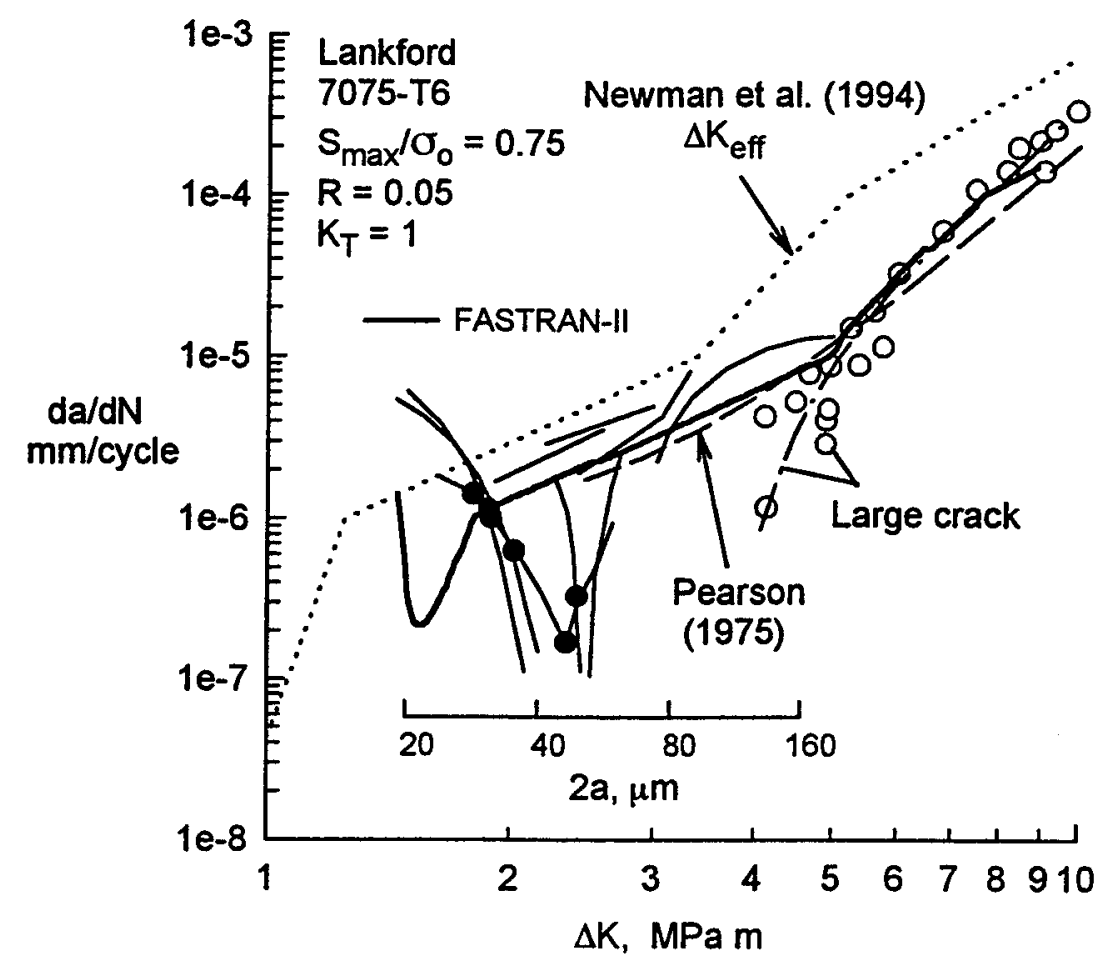

FIG. 21(b)--Measured and predicted small-crack growth in an aluminum alloy.

\section{PREDICTION OF FATIGUE LIFE USING SMALL-CRACK THEORY}

During the last decade, several international research programs have been conducted by the AGARD Structures and Materials Panel $[17,18,177,178]$, the National Aeronautics and Space Administration (NASA) [20] and the Chinese Aeronautical Establishment (CAE) [179] on small-crack effects in a wide variety of materials and loading conditions. A summary of the materials and loading conditions used to generate small-crack data on notched specimens is listed in Table 6. Most of these studies dealt with naturally-initiated cracks at notches but some studies $[177,178]$ used small electrical-discharged-machined notches to initiate cracks.

All materials listed in Table 6 were subjected to a wide range of stress ratios (R) under constant-amplitude loading. The 2024-T3 aluminum alloy $[17,18]$ was subjected to FALSTAFF, Inverted FALSTAFF, Gaussian, Felix-28, and TWIST loading; and the 7075-T6 alloy $[18,20,179]$ was subjected to the Gaussian and Mini-TWIST load spectra. The Lc9CS (a clad equivalent of 7075-T6) [20, 179] was subjected to Mini-TWIST loading. Aluminumlithium alloy 2090 [18] was subjected to the FALSTAFF, Gaussian, TWIST, and Felix-28 load sequences. The 4340 steel [18] was subjected to only the Felix-28 helicopter load sequence. The three titanium alloys (Ti-6Al-4V, IMI-685 and Ti-17) [177, 178] were subjected to only the Cold Turbistan spectrum. Details on these standardized spectra may be obtained from the appropriate references. 
TABLE 6--Materials and loading conditions used in various small-crack programs.

\begin{tabular}{ll}
\hline Materials & Loading Conditions (a) \\
\hline $2024-\mathrm{T} 3$ & Constant-amplitude \\
$7075-\mathrm{T} 6$ & FALSTAFF \\
Lc9CS (clad) & Inverted FALSTAFF \\
$2090-\mathrm{T} 8 \mathrm{E} 41$ & Gaussian \\
4340 & TWIST \\
Ti-6Al-4V & Mini-TWIST \\
IMI-685 & Felix-28 \\
Ti-17 & Cold Turbistan \\
& Commercial transport \\
\hline
\end{tabular}

(a) List of materials and loading conditions are not associated.

Newman and many of his coworkers $[17,20,163,180]$ used continuum-mechanics concepts with initial defect sizes, like those which initiated cracks at inclusion particles, voids or slip-bands, and the effective stress-intensity factor range (corrected for plasticity and closure) to predict the fatigue lives for many of the materials listed in Table 6. A summary of the initial defect sizes measured at numerous initiation sites is listed in Table 7. The baseline crack-growth rate data for these materials were obtained from the large-crack data, ignoring the large-crack threshold, and using small-crack growth rates at the extremely low rates. Small-crack thresholds were estimated from the endurance limit for the various materials. In the following, some typical examples of small-crack theory application will be presented.

\section{Aluminum Alloy 2024}

Landers and Hardrath [18I] conducted fati e tests on 2024-T3 aluminum alloy sheet material with specimens containing a central hole. The results are shown in Fig. 22 as symbols. Both elastic and elastic-plastic fatigue-crack growth analyses were performed. The solid and dashed curves show predictions using large-crack growth rate data (ignoring the large-crack threshold) and an initial crack size based on an average inclusion-particle size that initiated cracks [17]. The large-crack growth rate properties are given in Ref. 163 for the elastic stressintensity factor analysis. The crack-growth rate properties using the elastic-plastic effective stress-intensity factor analysis were obtained from a re-analysis of the large-crack data [182]. Both predictions agreed near the fatigue limit but differed substantially as the applied stress approached the flow stress $\left(\sigma_{\mathrm{o}}=425 \mathrm{MPa}\right)$. In these predictions, a $\Delta \mathrm{K}$-effective threshold for small cracks was selected as $1.05 \mathrm{MPa} \mathrm{V}_{\mathrm{m}}$ (see Ref. 17). Using this threshold value and the 
TABLE 7--Average material defect sizes and equivalent area crack sizes (surface defect unless otherwise noted).

\begin{tabular}{lccc}
\hline Material & $\begin{array}{c}\text { Defect } \\
\text { Half-length, } \\
\mu \mathrm{m}\end{array}$ & $\begin{array}{c}\text { Defect } \\
\text { Depth, } \\
\mu \mathrm{m}\end{array}$ & $\begin{array}{c}\text { Equivalent Area Semi- } \\
\text { Circular Crack Radius, } \\
\mu \mathrm{m}\end{array}$ \\
\hline 2024-T3 & 3 & 12 & 6 \\
7075-T6 & 3 & 9 & 5.2 \\
Lc9CS (clad) & 77 (a) & 77 & 77 \\
2090-T8E41 & 3.5 & 11 & 6 \\
4340 & 8 & 13 & 10 \\
Ti-6Al-4V (sheet) & (b) & (b) & 0.5 (c) \\
Ti-6Al-4V (forging) & (b) & (b) & 15 (c) \\
\hline
\end{tabular}

(a) Corner crack at clad layer (clad thickness about $60-70 \mu \mathrm{m}$ ).

(b) No metallurgical examination of initiation sites was made.

(c) Value selected to fit fatigue data.

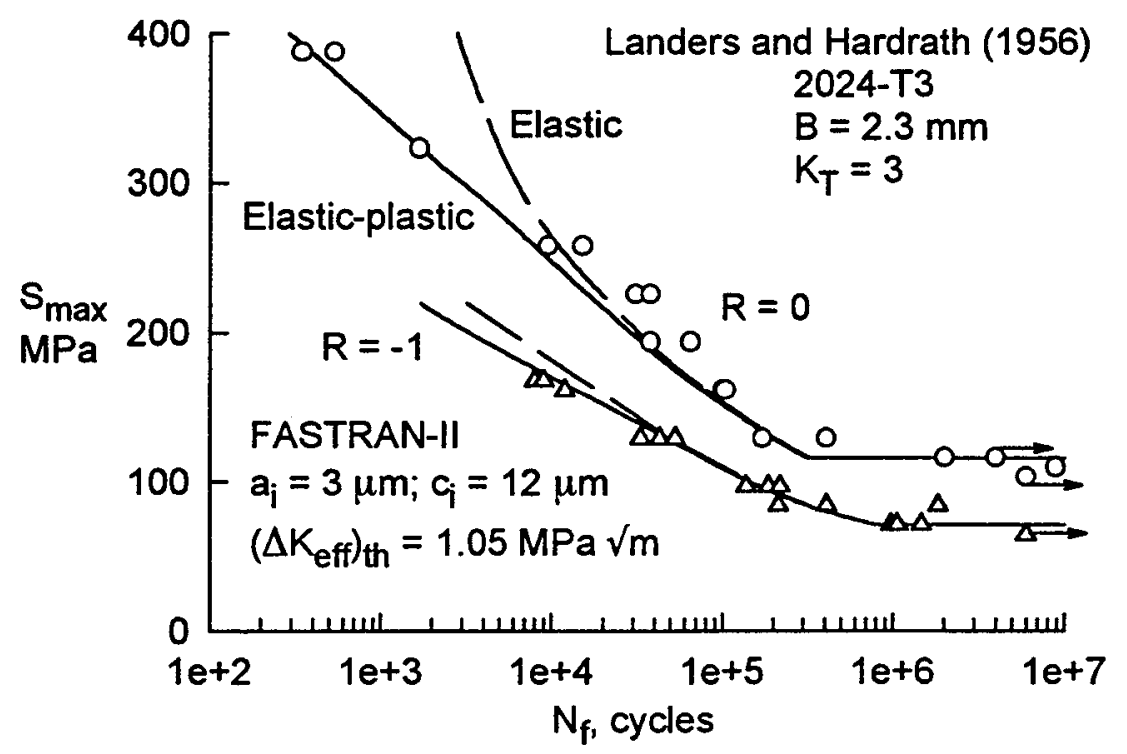

FIG. 22--Measured and predict fatigue lives for a hole in an aluminum alloy under constantamplitude loading (after Newman, 1992 [182]). 
initial defect size, the analysis were used to match the fatigue limits for the two $\mathrm{R}$ ratio tests. Above a stress level of about $250 \mathrm{MPa}$, the results from the elastic and elastic-plastic analyses differed substantially. The results from the elastic-plastic analyses agreed well with the test data and substantiated the use of the cyclic-plastic-zone corrected effective-stress-intensityfactor range [63]. Similar comparisons between measured and predicted S-N behavior for notched and un-notched aluminum alloy specimens subjected to either constant- or variableamplitude loading are presented in Reference 183.

Laz and Hillberry [184] conducted a study to address the influence of inclusions on fatigue-crack formation in 2024-T3 using a probabilistic model in conjunction with the FASTRAN-II code [150]. An examination of the microstructure produced data on nearly 3800 inclusions on the primary crack plane. A Monto Carlo simulation was conducted for 1000 trials. In each trial, an inclusion particle area is randomly selected and converted to an equivalent semi-circular initial crack size. The initial crack size, which was assumed to be located at the center of a single-edge-notch tension (SENT) specimen, was grown using the FASTRAN-II model. The probabilistic model produced a predicted distribution of fatigue lives. These results are presented in Fig. 23 as the solid curve and are compared with experimental data from the AGARD study [17] and other tests conducted by Laz and Hillberry. The probabilistic model accurately predicts both the mean and variation of the experimental results. Most importantly, however, the model predicted the critical lowest life values, which correspond to the largest, most damaging inclusions.

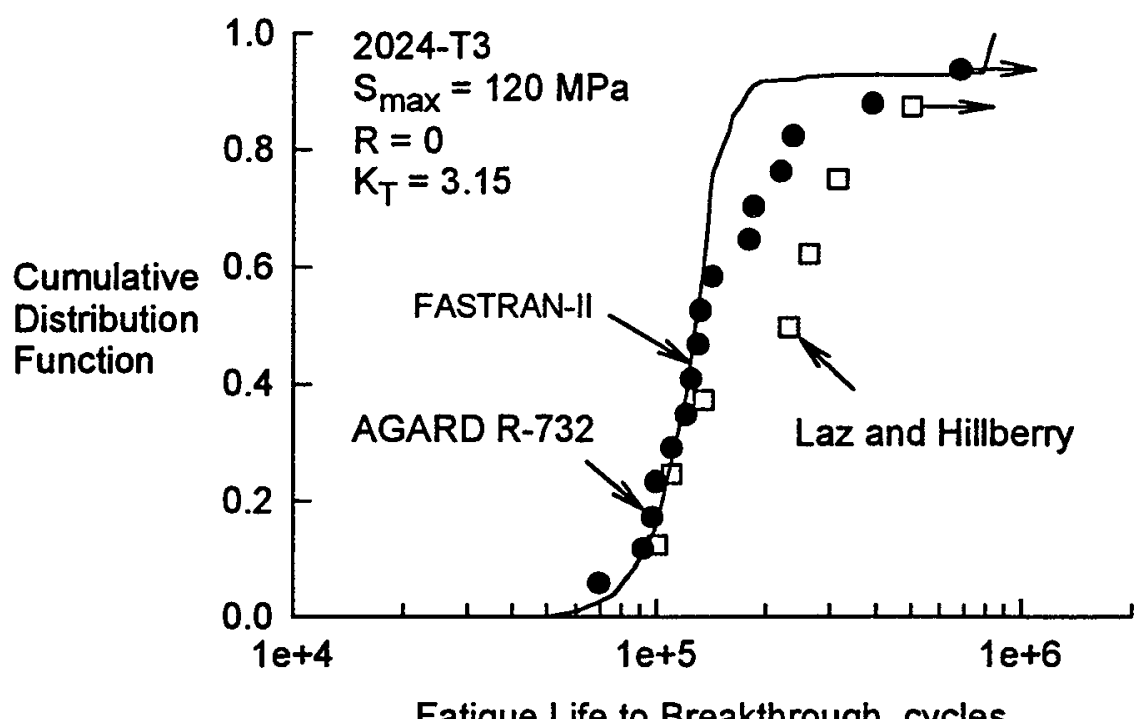

Fatigue Life to Breakthrough, cycles

FIG. 23-Measured and predicted cumulative distribution function for a notched aluminum alloy under constant-amplitude loading (after Laz and Hillberry, 1995 [184]). 


\section{High-Strength 4340 Steel}

Swain et al. [185] conducted fatigue and small-crack tests on 4340 steel, single-edgenotch tensile specimens. Tests were also conducted on large cracks to obtain the baseline crack-growth rate data. These tests were conducted under both constant-amplitude and spectrum loading. Only the results from the spectrum load fatigue tests will be discussed here.

The results of the fatigue life tests under the Felix-28 load sequence are shown in Fig. 24 as symbols. Inspection of the fracture surfaces showed that in each case a crack had initiated at an inclusion particle defect. Those specimens which had the shorter lives had cracks which initiated at spherical calcium-aluminate particle defects, whereas those with the longer lives had cracks which initiated at manganese sulfide stringer inclusion particle defects. Examination of the initiation sites for over 30 fatigue cracks produced information on the distribution of crack initiation site dimensions. The spherical particle defects range in size from 10 to $40 \mu \mathrm{m}$ in diameter. The stringer particles were typically 5 to $20 \mu \mathrm{m}$ in the thickness direction and range up to $60 \mu \mathrm{m}$ in length. The median values of the defect dimensions measured were $a_{i}=8 \mu \mathrm{m}$ and $c_{i}=13 \mu \mathrm{m}$.

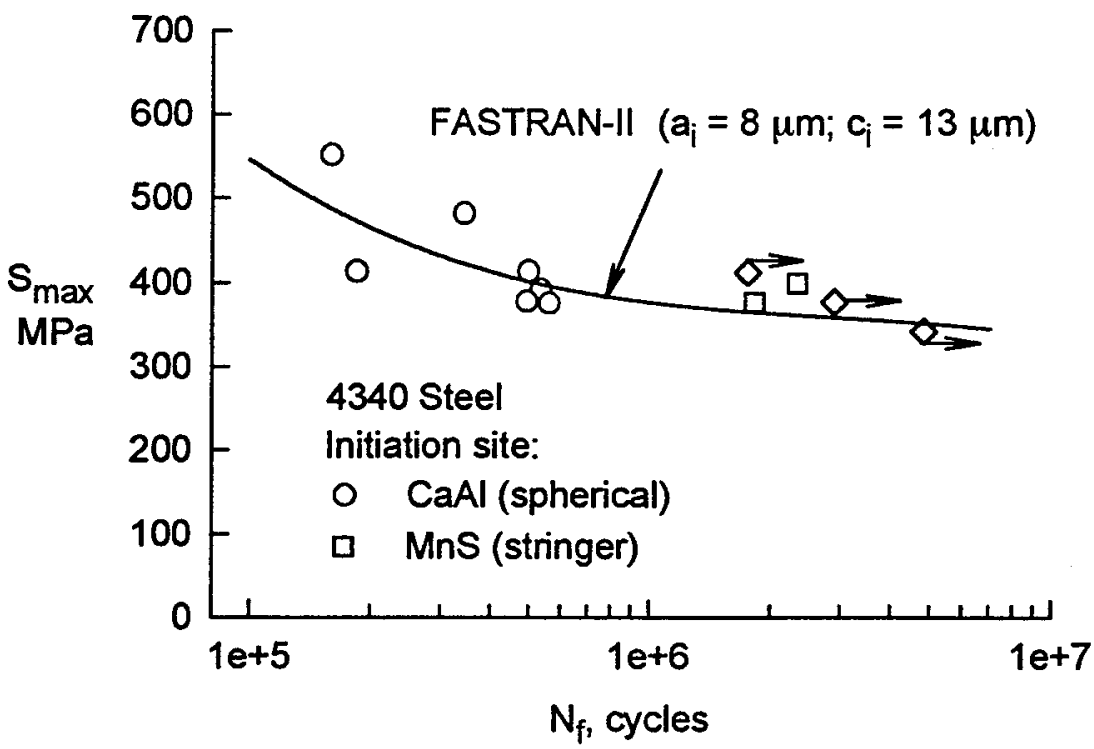

FIG. 24-Measured and predict fatigue lives for notched high-strength steel under helicopter spectrum loading, Felix/28 (after Swain et al., 1990 [185]).

Predictions of total fatigue life under the Felix-28 load spectrum were made using FASTRAN-II [156] by calculating the number of cycles necessary to grow a crack from the assumed initial defect size, located at the center of the notch root, to failure. The comparison between model predictions and experimental fatigue lives are shown in Fig. 24. The predicted results agreed well for those specimens which contained spherical 
defects as crack initiation sites. But, the predicted lives fell short for those specimens where cracks initiated from stringer inclusions or where no cracks of minimum size necessary for continued propagation were formed. Again, it is desirable to have good agreement for the larger spherical-inclusion particles because these particles will produce the minimum fatigue lives. For an engineering component, which may contain a large number of fastener holes or other areas of stress concentration, the likelihood of a critical sized inclusion particle being located at one of these sites is large.

\section{Titanium Alloy Ti-6Al-4V}

The titanium alloys listed in Table 7, the sheet and forging products, exhibited quite different behavior in terms of the equivalent initial flaw size (EIFS) required to fit the S-N data on notched specimens. For the sheet alloy, the EIFS was $0.5 \mu \mathrm{m}$ [180], whereas the forging alloy required a defect 2 to $20 \mu \mathrm{m}$ in depth to bound the scatter in tests on two different forgings. A comparison of the measured and calculated fatigue lives on the two titanium forgings are shown in Fig. 25. The fatigue test data generated on double-edge-notch tensile specimens made from the two forgings agreed well with each other. The FASTRAN-II life prediction code was used with large-crack growth rate data to calculate the fatigue lives from a selected initial semi-circular surface crack size, as shown by the solid curves (see Ref. 145). An average defect size of about $10 \mu \mathrm{m}$ would fit the mean of the experimental data quite well. (Note: An error was detected in the review process. The predicted S-N behavior, Fig. 20 in Ref. 145, was calculated at $R=0$ instead of 0.1 . Fig. 25 is a re-analysis of the $\mathrm{S}-\mathrm{N}$ behavior.)

Because no metallurgical examination of the fractured specimens was made to evaluate the initiation site in either References 178 or 186 , an attempt was made to relate the assumed initial crack size to some microstructural features (see Ref. 180). Because titanium has a relatively high solubility for most common elements and when multiple vacuum arc melting is accomplished with high purity materials, the occurrence of inclusion-type defects is rare. In a mill-annealed titanium alloy, Eylon and Pierce [187] studied the initiation of cracks and found that cracks preferred to nucleate in the width direction of alpha needles, or colonies of alpha needles, along a shear band on the basal plane. The size of the alpha needles was not reported but was stated to be considerably smaller than the size of alpha grains (grains were about $8 \mu \mathrm{m}$ in size). Thus, the alpha needle size may be close to the initial crack size needed to predict most of the fatigue life based solely on crack propagation. For the forging alloy, Wanhill and Looije [188] found that the primary $\alpha$-grains and platelet $\alpha$-packets ranged from 8 to $18 \mu \mathrm{m}$. Whether these $\alpha$-grains or packets contributed to the early initiation of micro-crack growth in the titanium forgings must await further study.

\section{DESIGN CONCEPT USING SMALL-CRACK THEORY}

The research that has occurred over the last two decades on "small- or micro-" crack growth has evolved into a new design concept that provides an alternative to the traditional safe-life (or S-N) approach. The diagram in Fig. 26 shows the various design concepts: Safe- 


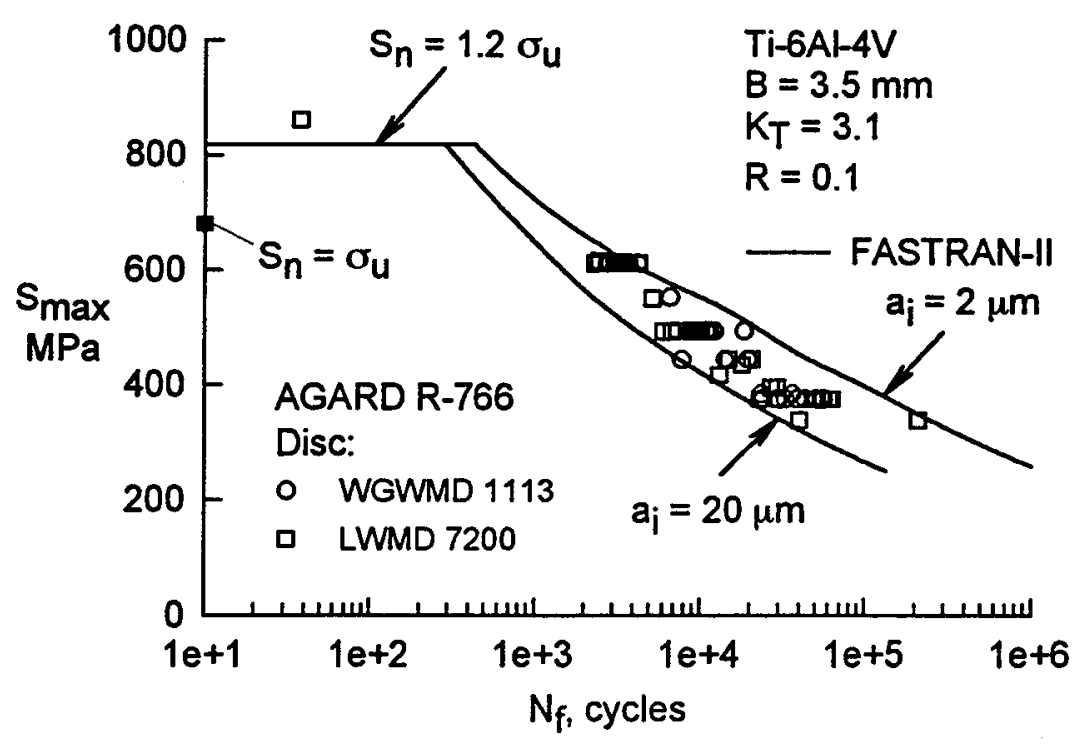

FIG. 25--Measured and calculated fatigue lives for a double-edge-notch tensile specimen under constant-amplitude loading (modified after Newman et al., 1994 [145]).

life, Small-crack theory, Durability, Damage tolerance, and Fail-safe, and their relative location with respect to flaw size. The flow in the diagram, from safe-life to the fail-safe concept, depicts crack formation, micro-crack growth, macro-crack growth, and fracture.

One of the original design concepts used in the aerospace industry was "safe-life", see Reference 22. Here a structure was assumed to be defect free and the life was established by conventional S-N or $\varepsilon-\mathrm{N}$ approaches. A safe-life component is retired from service when its useful life has been expended. More recently, the total life has been calculated from a crackinitiation period $\left(\mathrm{N}_{\mathrm{i}}\right)$ and a crack-propagation period $\left(\mathrm{N}_{\mathrm{p}}\right)$, see Reference 189. However, the crack size existing after the initiation period was debatable. In practice, however, it has been found that preexisting manufacturing defects (i.e., scratches, flaws, burrs, and cracks) or service induced damage (i.e., corrosion pits) are very often the source of structural cracking problems. The effect of these defects on the life of a component was dependent on the defects initial size, the rate of crack growth with service usage, and the critical crack size.

From these considerations, the "damage-tolerance" design philosophy [190] was developed. The damage-tolerance approach assumes that a component has prior damage or a flaw size that is inspectable. Useful service life is then some specified portion of the crack propagation life required to grow the crack from the inspectable size to failure.

The durability design concept [191] is economic-life extension to minimize in-service maintenance costs and to maximize performance. The durability analysis methodology, based on a probabilistic fracture mechanics approach, accounts for the initial fatigue quality (i.e., surface treatment, manufacturing defects), fatigue-crack growth in a population of structural details, load spectra, and structural design details. A statistical distribution of the "equivalent 


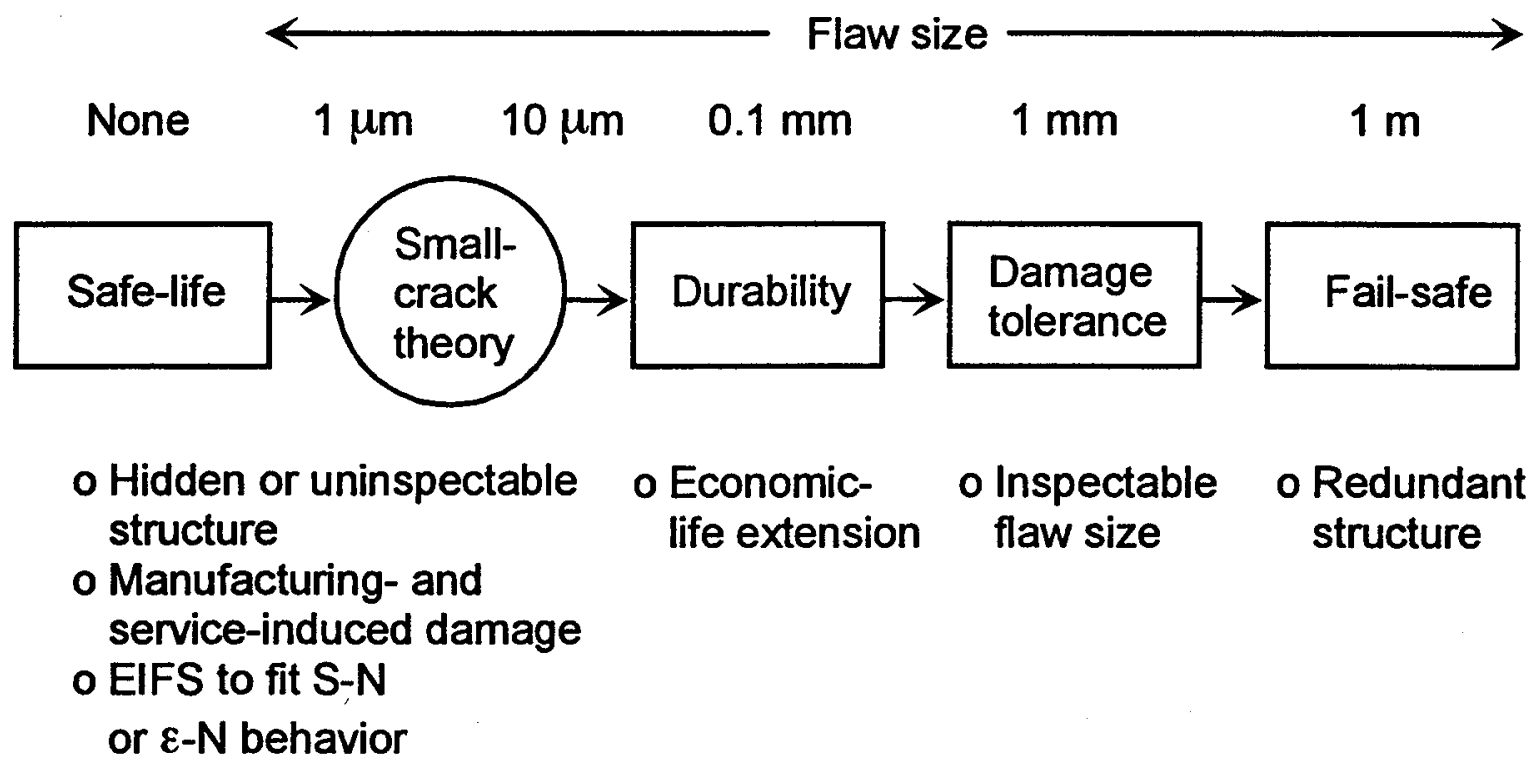

FIG. 26--Evolution of design concepts in relation to "small-crack theory."

initial flaw sizes" (EIFS) is used to represent the initial fatigue quality of structural details. In practice, the EIFS distributions have ranged from 0.1 to $0.5 \mathrm{~mm}$. As the EIFS's become smaller (below about $1 \mathrm{~mm}$ ), the question of small-crack effects is raised. The current durability methodology, which does not account for small-crack effects, masks the small-crack behavior by deriving an EIFS that predicts the desired crack-propagation life. However, EIFS variability with load spectra may be resolved if small-crack theory is implemented into the design practice.

The evolution of "safe-life" and "durability/damage-tolerance" design concepts have both moved in the direction of "small-crack behavior." As inspection techniques and manufacturing quality improves, smaller flaw sizes will be detected or produced in manufacturing. The design of uninspectable or hidden structures, or structures subjected to an extremely large number of cyclic loads (i.e., engines and helicopter components) must relie on approaches that deal with the growth of small cracks.

"Small-crack theory" is currently used to assess the structural fatigue life at two levels of initial flaw sizes. First, it is used to assess the initial design quality of a structure based solely on "material" microstructural properties, such as cracks growing from inclusion particles, voids, grains, grain boundaries or cladding layers. Of course, this crack-growth life is the best the current material can provide under the desired loading. In the second level of calculations, as in the durability analysis, a manufacturing or service-induced flaw size is used with smallcrack theory. But the effects of small-crack growth are now accounted for in the analysis (i.e., faster growth rates at a given $\Delta K$ and growth below the large-crack threshold). Small-crack theory can now be used to evaluate EIFS for various spectra and structural details; and to characterize S-N or $\varepsilon-\mathrm{N}$ behavior. The impact of small-crack effects on design-life calculations have been discussed by Phillips and Newman [192]. 


\section{SUMMARY - Past, Present and Future}

A summary of the observations as well as past, present and potential future approaches concerning fatigue concepts, crack-propagation concepts, and small- (or micro-) crack growth behavior has been made. In the past, fatigue was characterized by stress-life (S-N) or strain-life $(\varepsilon-\mathrm{N})$ curves; and crack propagation was characterized by the $\Delta \mathrm{K}$-rate concept. It was observed that small cracks initiated early in life at high stress levels, but initiated late in life at low stress levels (near the endurance limit). Thus, initiation life was dominate near the endurance limit. At present, fatigue is characterized by a crack initiation stage $\left(\mathrm{N}_{\mathrm{i}}\right)$ and a crack-propagation stage $\left(\mathrm{N}_{\mathrm{p}}\right)$; and crack propagation is characterized by the effective cyclic stress-intensity factor $\left(\Delta \mathrm{K}_{\text {eff }}\right)$ or J-integral $\left(\Delta \mathrm{J}_{\mathrm{eff}}\right)$. Small cracks grow faster than large cracks; and small cracks grow at stress-intensity factor $(\Delta \mathrm{K})$ levels well below the large-crack threshold $\left(\Delta \mathrm{K}_{\mathrm{th}}\right)$.

Proposed future approaches are: (1) fatigue damage is characterized by crack size and fatigue lives are calculated by crack propagation from a micro-crack size, (2) crack growth is characterized by a local nonlinear crack-tip stress or deformation parameter, such as J, $\mathrm{T}^{*}$, $\triangle \mathrm{CTOD}$ or cyclic hysteresis energy, (3) small-crack growth is viewed as the typical behavior and large-crack growth near and at threshold is the anomaly on a $\Delta \mathrm{K}$ basis, and (4) fatigue life prediction methods need to be developed to predict micro-crack growth, as influenced by microstructure and environment, under complex load histories. The proposed approaches will potentially bridge the gap between "safe life" and "durability/damage tolerance" concepts.

\section{REFERENCES}

[1] Swedlow, J. L., Ph.D. Thesis, California Institute of Technology, Pasadena, CA, 1965.

[2] Cohen, B., Farren, W., Duncan, W. and Wheeler, A., "Report of the Court of Inquiry into the Accidents to Comet G-ALYP on 10 January 1954 and Comet G-ALYY on 8 April 1954," HMSO, London, 1955.

[3] Irwin, G. R., Journal of Applied Mechanics, Vol. 24, 1957, pp 361-364.

[4] Paris, P., Gomez, M. and Anderson, W., The Trend in Engineering, Vol. 13, 1961, p 9.

[5] Paris, P. C. and Erdogan, F., Journal of Basic Engineering, Vol. 85, 1963, p 528.

[6] Neuber, H., Journal of Applied Mechanics, Vol. 28, No. 4, 1961, pp 544-550.

[7] Hardrath, H. F. and Ohman, L., NACA TR 1117, 1953.

[8] Hutchinson, J. W., Journal of Mechonics and Physics of Solids, Vol. 16, 1968, p 13. -

[9] Rice, J. R., Journal of Applied Mechanics, June 1968, pp 379-386.

[10] McEvily, A. J., Jr. and Illg, W., NACA TN 4394, 1958.

[11] Elber, W., in ASTM STP 486, 1971, pp 230-242.

[12] Pearson, S., Engineering Fracture Mechanics, Vol. 7, No. 2, 1975, pp 235-247.

[13] Kitagawa, H. and Takahashi, S., in Proceedings of 2nd International Conference on Mechanical Behavior of Materials, Boston, MA, 1976, pp 627-631.

[14] Ritchie, R. O. and Lankford, J., eds., Small Fatigue Cracks, The Metallurgical Society, Inc., Warrendale, PA, 1986. 
[15] Miller, K. J. and de los Rios, E. R., eds., The Behaviour of Short Fatigue Cracks, European Group on Fracture, Publication No. 1, 1986.

[16] Zocher, H., ed., AGARD CP-328, 1983.

[17] Newman, J. C., Jr. and Edwards, P. R., AGARD Report No. 732, 1988.

[18] Edwards, P. R. and Newman, J. C., Jr., eds., AGARD Report No. 767, 1990.

[19] Larsen, J. M. and Allison, J. E., eds., ASTM STP 1149, 1992.

[20] Newman, J. C., Jr.; Wu, X. R.; Venneri, S. L and Li, C. G., NASA RP-1309, 1994.

[21] Lankford, J., Fatigue of Engineering Materials and Structures, Vol. 5, 1982, p 233.

[22] Fuchs, H. and Stephens, R., Metal Fatigue in Engineering, John Wiley and Sons, 1980.

[23] Smith, R. A., ed., Fatigue Crack Growth, Pergamon Press, New York, 1986.

[24] Schütz, W., Engineering Fracture Mechanics, Vol. 54, No. 2, 1996, pp 263-300.

[25] Paris, P. C., in ASTM STP 1207, J. Landes, D. McCabe and J. Boulet, eds., 1994, p 5.

[26] Schijve, J., in ASTM STP 415, 1967, pp 415-459.

[27] Schijve, J., Engineering Fracture Mechanics, Vol. 11, 1979, pp 167-221.

[28] Forsyth, P. J. E., in Proceedings of Crack Propagation Symposium, Vol. I, Cranfield College of Aeronautics, Cranfield, UK, 1961, pp 76-94.

[29] Bowles, C. Q. and Schijve, J., International Journal of Fracture, Vol. 9, 1973, p 171.

[30] Morris, W., Buck, O. and Marcus, H., Metallurgical Transactions, Vol. 7A, August 1976, pp 1161-1165.

[31] Kung, C. Y. and Fine, M. E., Metallurgical Transactions, Vol. 10A, 1979, p 603.

[32] Hunter, M. S. and Fricke, W. G., Jr., in Proceedings of the American Society for Testing and Materials, Vol. 56, 1956, pp 1038-1046.

[33] Elber, W., Ph.D. Thesis, University of New South Wales, 1968.

[34] Walker, N. and Beevers, C. J., Fatigue of Engineering Materials and Structures, Vol. 1, No. 1, 1979, pp 135-148.

[35] Halliday, M. D. and Beevers, C. J., International Journal of Fracture, Vol. 15, p R27.

[36] Suresh, S. and Ritchie, R. O., Metallurgical Transactions, Vol. 13A, September 1982, pp 1627-1631.

[37] Paris, P. C., Bucci, R. J., Wessel, E. T., Clark, W. G. and Mager, T. R., in ASTM STP 513, 1972, pp 141-176.

[38] Suresh, S., Parks, D. and Ritchie, R., in Proceedings Symposium on Fatigue Thresholds, J. Backlund, A. Blom, and C. Beevers, EMAS Ltd., Warley, UK, 1982, pp 391-408.

[39] Irwin, G. R., in 9th International Congress Applied Mechanics, Brussels, Vol. 8, 1956, p 245-251.

[40] Williams, M. L., Journal of Applied Mechanics, Vol. 24, 1957, pp 109-114.

[41] Tada, H., Paris, P. C. and Irwin, G. R., The Stress Analysis of Cracks Handbook, Del Research Corporation, Bethlehem, PA, 1985.

[42] Murakami, Y., ed., Stress Intensity Factors Handbook, Pergamon Press, 1987.

[43] Raju, I. S. and Newman, J. C., Jr., Engineering Fracture Mechanics, Vol. 11, No. 4, 1979, pp 817-829.

[44] Newman, J. C., Jr. and Raju, I. S., in Computational Methods in the Mechanics of Fracture, S. N. Atluri, ed., Elsevier, 1986, pp 311-334. 
[45] Rice, J. R. and Rosengren, G. F., Journal Mechanics and Physics of Solids, Vol. 16, 1968, pp 1-12.

[46] Eshelby, J. D., Solid State Physics, Vol. 3, Academic Press, New York, 1956, p 79-144.

[47] Sanders, J. L., Journal of Applied Mechanics, Vol. 27, 1960, pp 352-353.

[48] Cherepanov, G. P., Applied Mathematics and Mechanics, Vol. 31, No. 3, 1967, pp 467-488.

[49] Landes, J. D. and Begley, J. A, in ASTM STP 514, 1972, pp 24-39.

[50] Cherepanov, G. P., International Journal Solids and Structures, Vol. 25, 1989, p 1267.

[51] Atluri, S. N., Engineering Fracture Mechanics, Vol. 16, 1982, pp 341-364.

[52] Atluri, S. N., Nishioka, T. and Nakagaki, M., Engineering Fracture Mechanics, Vol. 20, No. 2, 1984, pp 209-244.

[53] Dowling, N. E. and Begley, J. A., in ASTM STP 590, 1976, pp 82-103.

[54] Dowling, N. E., in ASTM STP 601, 1976, pp 19-32.

[55] Kumar, K., Dattaguru, B., Ramamurthy, T., Prakash, R., and Raju, K., in 27th National Symposium on Fatigue and Fracture Mechanics, Williamsburg, VA, 1996.

[56] Irwin, G. R., in Proceedings 7th Sagamore Conference, 1960, pp IV.63-IV.76.

[57] McClintock, F. A. and Irwin, G. R., in ASTM STP 381, 1965, pp 84-113.

[58] Dugdale, D. S., Journal of the Mechanics and Physics of Solids, Vol. 8, 1960, p 100.

[59] Barenblatt, G. I., Advances in Applied Mechanics, Vol. 7, 1962, pp 55-129.

[60] Newman, J. C., Jr., Engineering Fracture Mechanics, Vol. 1, 1968, pp 137-154.

[6I] Chan, K. S., in Small Fatigue Cracks, The Metallurgical Society, Inc., Warrendale, PA, 1986, pp 407-426.

[62] Drucker, D. C. and Rice, J. R., Engineering Fracture Mechanics, Vol. 1, 1970, p 577.

[63] Newman, J. C., Jr., in ASTM STP 1149, J. Larsen and J. E. Allison, eds., 1992, p 6.

[64] Hudak, S. J., Jr. and Chan, K. S., in Small Fatigue Cracks, The Metallurgical Society, Inc., Warrendale, PA, 1986, pp 379-406.

[65] Hudak, S. J., Jr. and Page, R. A., Corrosion - NACE, Vol. 39, July 1983, pp 287-290.

[6] Newman, J. C., Jr., Ph.D. Thesis, VPI\&SU, Blacksburg, VA, May 1974.

[67] Newman, J. C., Jr. and Armen, H., Jr., AIAA Journal, Vol. 13, Aug. 1975, p 1017.

[68] Newman, J. C., Jr., in ASTM STP 490, 1976, p 281.

[69] Ohji, K., Ogura, K. and Ohkubo, Y., Engineering Fracture Mechanics, Vol. 7, 1975, pp 457-464.

[70] Nakagaki, M. and Atluri, S. N., AIAA Journal, Vol. 18, 1980, pp 1110-1117.

[7I] Anquez, L., La Recherche Aerospatiale, Report No. 1983-2, 1983.

[72] Blom, A. F. and Holm, D. K., Engineering Fracture Mechanics, Vol. 22, 1985, pp 997.

[73] Kobayashi, H. and Nakamura, H., in Current Research on Fatigue Cracks, The Society of Materials Science (Japan), 1985, pp 201-215.

[74] Lalor, P., Sehitoglu, H. and McClung, R. C., in The Behovior of Short Fatigue Cracks, EFG 1, Mechanical Engineering Publications, London, 1986, pp 369-386.

[75] Bednarz, E., Ph.D. Thesis, Air Force Institute of Technology, 1986.

[76] Fleck, N. A., Engineering Fracture Mechanics, Vol. 25, 1986, pp 441-449.

[77] Nicholas, T., Palazotto, A. N. and Bednarz, E., in ASTM STP 982, 1988, pp 361-379. 
[78] Anquez, L. and Boudin, G., in ASTM STP 982, 1988, pp 380-397.

[79] Fleck, N. A. and Newman, J. C., Jr., in ASTM STP 982, 1988, pp 319-341.

[80] McClung, R. C. and Sehitoglu, H., Engineering Fracture Mechanics, Vol. 33, 1989, pp 253-272.

[81] McClung, R. C., in Theoretical Concepts and Numerical Analysis of Fatigue, A. Blom and C. Beevers, eds., Engineering Materials Advisory Services, Ltd., 1992, p 153.

[82] McClung, R. C., Fatigue and Fracture of Engineering Materials and Structures, Vol. 17, 1994, pp 861-872.

[83] Llorca, J. and Galvez, S., Engineering Fracture Mechanics, Vol. 37, 1990, p 185.

[84] Llorca, J., Fatigue and Fracture of Engineering Materials and Structures, Vol. 15, 1992, pp 655-669.

[85] Sehitoglu, H., Gall, K. and Garcia, A. M., International Journal of Fracture, Vol. 80, No. 2-3, 1996, pp 165-192.

[86] Chermahini, R. G, Ph.D. Thesis, Old Dominion University, Norfolk, VA, 1986.

[87] Chermahini, R. G., Shivakumar, K. N. and Newman, J. C., Jr., in ASTM STP 982, 1988, pp 398-413.

[88] Chermahini, R. G. and Blom, A. F., Theoretical and Applied Fracture Mechanics, Vol. 15, 1991, pp 267-276.

[89] Newman, J. C., Jr., International Journal of Fracture, Vol. 24, 1984, pp R131-R135.

[90] Dawicke, D., Shivakumar, K., Newman, J., and Grandt, A., in ASTM STP 1131, Vol. II, 1992, pp 46-57.

[91] Sunder, R and Dash, P. K., International Journal of Fatigue, Vol. 4, 1982, pp 97-105.

[92] Wheeler, O. E., Journal of Basic Engineering, 1972, pp 181-186.

[93] Willenborg, J. D., Engle, R. M. and Wood, H. A., AFFDL-TM-71-1-FBR, Dayton, OH, January 1971.

[94] Gallagher, J. P., AFFDL-TM-74-28-FBR, Dayton, OH, January 1974.

[95] Chang, J. B., Engle, R. M. and Stolpestad, J., in ASTM STP 743, 1981, pp 3-27.

[96] Johnson, W. S., in ASTM STP 748, 1981, pp 85-102.

[97 Harter, J. A., AFWAL-TM-88-157-FIBE, February 1988 (Revised July 1994).

[98] Bell, P. D. and Wolfman, A., in ASTM STP 595, 1976, pp 157-171.

[99] Schijve, J., in ASTM STP 700, 1980, pp 3-34.

[100] De Koning, A. U., in ASTM STP 743, 1981, pp 63-85.

[101] Baudin, G. and Robert, M., in Proceedings of the Fifth European Conference on Fracture, Lisbon, Spain, 1984, pp 779-792.

[102] Aliaga, D., Davy, A. and Schaff, H., in Durability and Damage Tolerance in Aircraft Design, EMAS Ltd., Warley, UK, 1985, pp 605-630.

[103] Chang, J. B. and Hudson, C. M., eds., ASTM STP 748, 1981.

[104] Lazzeri, L., Pieracci, A and Salvetti, A., in 18th Symposium of International Committee on Aeronautical Fatigue, Melbourne, Australia, May 1995.

[105] Wanhill, R. J. H., International Journal of Fatigue, Vol. 16, 1994, pp 99-110.

[106] Newman, J. C., Jr., in Fatigue of Aircraft Materials, A. Beukers, T. deJong, J. Sinke, A. Vlot and L. B. Vogelesang, eds., Delft University Press, 1992, pp 83-109. 
[107 Seeger, T., Institut fur Statik und Stahlbau, Report No. 21, Darmstadt, Germany, 1973. [108] Dill, H. D. and Saff, C. R., in ASTM STP 595, 1976, pp 306-319.

[109] Budiansky, B. and Hutchinson, J. W., Journal of Applied Mechanics, Vol. 45, 1978, pp 267-276.

[110] Hardrath, H. F., Newman, J. C., Jr., Elber, W. and Poe, C. C., Jr., in Fracture Mechanics, N. Perrone, Liebowitz, H., Mulville, D. and Pilkey, W., eds., University of Virginia Press, 1978, pp 347-364.

[11I] Fuhring, H. and Seeger, T., Engineering Fracture Mechanics, Vol. 11, 1979, p 99.

[112] Newman, J. C., Jr., in ASTM STP 748, 1981, pp 53-84.

[113] Nakai, Y., Tanaka, K. and Yamashita, M., Journal Society of Material Science, Japan, Vol. 32, 1983, pp 19-25.

[114] Sehitoglu, H., Engineering Fracture Mechanics, Vol. 21, No. 2, 1985, pp 329-339.

[115] Keyvanfar, F., Ph.D. Thesis, Stanford University, Stanford, CA, August 1985

[116] Tanaka, K., in Small Fatigue Cracks, The Metallurgical Society, Inc., 1986, p 343.

[117] Ibrahim, F. K., Ph.D. Thesis, University of Waterloo, Waterloo, Canada, 1986.

[118] Wang, G. S. and Blom, A. F., The Aeronautical Research Institute of Sweden, Report FFA TN 1987-79, 1987.

[119] Keyvanfar, F. and Nelson, D. V., in ASTM STP 982, 1988, pp 414-436.

[120] deKoning, A. U. and Liefting, G., in ASTM STP 982, 1988, pp 437-458.

[12I] Nakamura, H. and Kobayashi, H., in ASTM STP 982, 1988, pp 459-474.

[122] Chen, D. H. and Nisitani, H., in ASTM STP 982, 1988, pp 475-488.

[123] Wang, G. S. and Blom, A. F., Engineering Fracture Mechanics, Vol. 40, 1991, p 507.

[124] Daniewicz, S. R., Ph.D. Thesis, Ohio State University, 1991.

[125] ten Hoeve, H. J. and de Koning, A. U., NLR CR 95399 L, The Netherlands, 1995.

[126] Blauel, J. G. and Schwalbe, K., eds., Defect Assessment in Components - Fundamentals and Applications, ESIS/EGF 9, Mechanical Engineering Publication Ltd., 1991.

[127] Hackett, E., Schwalbe, K. and Dodds, R, eds., ASTM STP 1171, 1993.

[128] Kirk, M. and Bakker, A, eds., ASTM STP 1244, 1995.

[129] McClintock, F. A., Journal of Applied Mechanics, June 1968, pp 363-371.

[130] Rice, J. and Tracey, D. M., Journal of the Mechanics and Physics of Solids, Vol. 17, 1969, pp 201-217.

[131] Sommer, E. and Aurich, D., in Defect Assessment in Components - Fundamentals and Applications, ESIS/EGF 9, J. G. Blauel and K. -H. Schwalbe, eds., 1991, pp 141-174.

[132] Larsson, S. G. and Carlsson, A. J., Journal of the Mechanics and Physics of Solids, Vol. 21, 1973, pp 263-278.

[133] Betegon, C. and Hancock, J. W., Journal of Applied Mechanics, Vol. 58, 1991, p 104.

[134] Li, Y. and Wang, Z., Scientia Sinica (Series A), Vol. 29, 1986, pp 941-955.

[135] O'Dowd, N. P. and Shih, C. F., Journal of Mechanics and Physics of Solids, Vol. 39, 1991, pp 989-1015.

[136] O'Dowd, N. P. and Shih, C. F., Journal of Mechanics and Physics of Solids, Vol. 40, 1992, pp 939-963. 
[137] Yang, S., Chao, Y. J. and Sutton, M. A., Engineering Fracture Mechanics, Vol. 45, 1993, pp 1-20.

[138] Chao, Y. J., Yang, S. and Sutton, M. A., Journal of Mechanics and Physics of Solids, Vol. 42, 1994, pp 629-647.

[139] Newman, J. C., Jr., Engineering Fracture Mechanics, Vol. 5, 1973, pp 667-689.

[140] Newman, J. C., Jr., in Proceedings of the Tenth Anniversary Meeting of the Society of Engineering Science, Raleigh, N. C., 1973, pp 67-74.

[14I] Sadowsky, M. and Sternberg, E., Journal of Applied Mechanics, Vol. 16, 1949, p 149.

[142] Kuhn, P. and Figge, I. E., NASA TN D-1259, 1962.

[143] Merkle, J. G., in ASTM STP 1256, 1995, pp 3-40.

[144] Newman, J. C., Jr., Bigelow, C. A. and Shivakumar, K. N., Engineering Fracture Mechanics, Vol. 46, No. 1, 1993, pp 1-13.

[145] Newman, J. C., Jr., Phillips, E. P. and Everett, R. A., Jr., in AGARD Report No. 797, 1994, pp 2.1-2.13.

[146] Head, A. K., Philosophical Magazine, Vol. 44, pp 925-928.

[147] Donaldson, D. R. and Anderson, W. E., in Proceedings of the Crack Propagation Symposium, Vol. II, Cranfield College of Aeronautics, 1962, pp 375-441.

[148] Forman, R. G., Kearney, V. E. and Engle, R. M., Journal of Basic Engineering, Vol. 89, No. 3, 1967, pp 459-464.

[149] Walker, K., in ASTM STP 462, 1970, pp 1-14.

[150] Elber, W., Engineering Fracture Mechanics, Vol. 2, No. 1, 1970, pp 37-45.

[15I] Tomkins, B., Philosophical Magazi Vol. 18, 1968, pp 1041-1066.

[152] Bilby, B. A, Cottrell, A. H. and Swinden, K. H., in Proceedings of the Royal Society A, Vol. 272, 1963, p 304.

[153] Ogura, K., Miyoshi, Y. and Nishikawa, I., in Current Research on Fatigue Cracks, T. Tanaka, M. Jono, and K. Komai, eds., Society of Materials Science, Japan, 1985, p 57.

[154] Miller, M. S. and Gallagher, J. P., in ASTM STP 738, 1981, pp 205-251.

[155] Forman, R., Shivakumar, V., Newman, J., Piotrowski, S. and Williams, L., in ASTM STP 945, 1988, pp 781-803.

[156] Newman, J. C., Jr., NASA TM-104159, February 1992.

[157] Yoder, G. R., Cooley, L. A. and Crooker, T. W., Scripta Metallurgica, Vol. 16, 1982, pp 1021-1025.

[158] Piascik, R. S. and Gangloff, R. P., Metallurgical Transactions, Vol. 24A, December 1993, pp 2751-2762.

[159] Petit, J. and Henaff, G., Scripta Metallurgica, Vol. 25, 1991, pp 2683-2687.

[160] Petit, J. and Henaff, G., in Fatigue 93, J. Bailon and Dickson, J., eds., 1993, p 503.

[161] Newman, J. C., Jr., in AGARD CP-328, 1983, pp 6.1-6.26.

[162] Minakawa, K. and McEvily, A. J., in Proceedings International Conference on Fatigue Thresholds, Vol. 2, Stockholm, Sweden, 1981, pp 373-390.

[163] Newman, J. C., Jr., Swain, M. H. and Phillips, E. P., in Small Fatigue Cracks, The Metallurgical Society, Inc., Warrendale, PA, 1986, pp 427-452.

[164] Schijve, J., Delf University of Technology, Report LR-287, Sept. 1979. 
[165] Wilhem, D. P., in ASTM STP 415, 1967, pp 363-383.

[160] Hudson, C. M., NASA TN D-5390, 1969.

[167] Phillips, E. P., in ASTM STP 982, pp 505-515.

[168] Dubensky, R. G., NASA CR-1732, 1971.

[169] Wanhill, R. J. H., NLR TR 77092 U, July 1977.

[170] Wanhill, R. J. H., Fatigue of Engineering Materials and Structures, Vol. 1, 1979, p 5.

[17I] Ritchie, R. O. and Lankford, J., in Small Fatigue Cracks, The Metallurgical Society, Inc., Warrendale, PA, 1986, pp 1-5.

[172] Miller, K. J., Fatigue and Fracture of Engineering Materials and Structures, Vol. 10, No. 1, 1987.

[173] El Haddad, M. H., Dowling, N. E., Topper, T. H. and Smith, K. N., International Journal of Fracture, Vol. 16, 1980, pp 15-30.

[174] Trantina, G. G. and Barishpolsky, M., Engineering Fracture Mechanics, Vol. 20, 1984, pp 1-10.

[175] Schijve, J., in Proceedings 2nd International Conference on Fatigue and Fatigue Thresholds, University of Birmingham, September 1984.

[176] Lankford, J., Fatigue of Engineering Material and Structures, Vol. 6, 1983, pp 15-32.

[177] Mom, A. J. A. and Raizenne, M. D., eds., AGARD Report 766, August 1988.

[178] AGARD Engine Disc Cooperative Programme, AGARD Report 766 (Addendum), April 1993.

[179] Selected Papers in Scientific and Technical International Cooperation Program, C. Zhihua, ed., Chinese Aeronautical Establishment, No. 5, Aviation Industry Press, 1994.

[180] Newman, J. C., Jr., Phillips, E. P., Swain, M. H. and Everett, R. A., Jr., ASTM STP 1122, 1992, pp 5-27.

[181] Landers, C. B. and Hardrath, H. F., NACA TN-3631, March 1956.

[182] Newman, J. C., Jr., in Theoretical Concepts and Numerical Analysis of Fatigue, A. F. Blom and C. J. Beevers, eds., EMAS, Ltd., 1992, pp 301-325.

[183] Newman, J. C., Jr., Fatigue and Fracture of Engineering Materials and Structures, Vol. 17, 1994, pp 429-439.

[184] Laz, P. J. and Hillberry, B. M., in Fatigue 96, Lutjering G. and Nowack, H., eds., Berlin, Germany, May 1996.

[185] Swain, M. H., Everett, R. A., Jr., Newman, J. C., Jr. and Phillips, E. P., in AGARD Report 767, 1990, pp 7.1-7.30.

[186] Lanciotti, A. and Galatolo, R., in AGARD Report 767, 1990.

[187] Eylon, D. and Pierce, C. M., Metallurgical Transactions, Vol. 7A, 1976, pp 111-121.

[188] Wanhill, R. and Looije, C., in AGARD Report 766 (Addendum), 1993, pp 2.1-2.40.

[189] Dowling, N. E., Mechanical Behavior of Materials, Prentice Hall, Inc., p 667.

[190] Gallagher, J., Giessler, F., Berens, A., and Engle, R., AFWAL-TR-82-3073, May 1984.

[191] Manning, S. D. and Yang, J. N., AFWAL-TR-83-3027, January 1984.

[192] Phillips, E. P. and Newman, J. C., Jr., Experimental Mechanics, June 1989, pp 221225. 


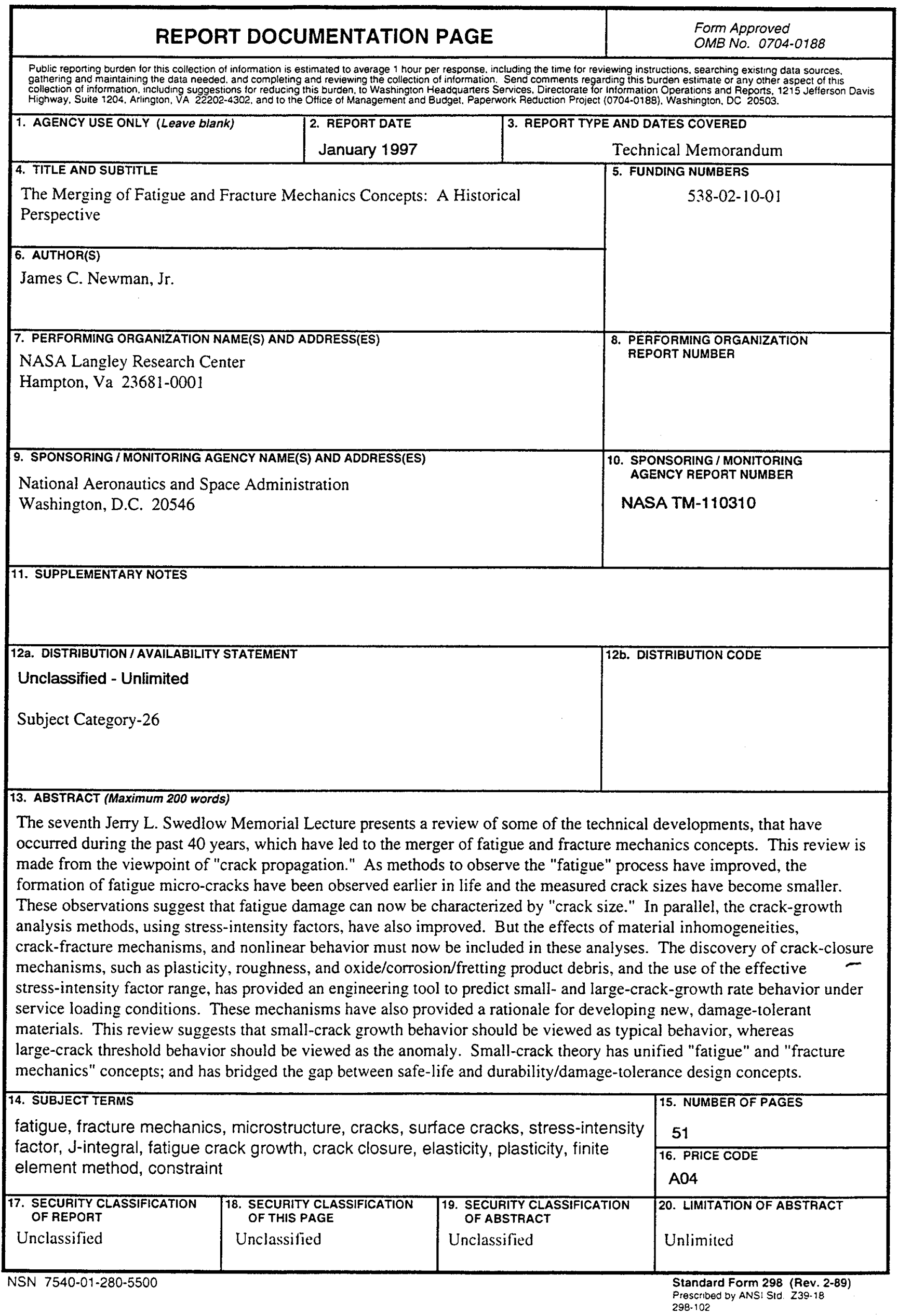

